\title{
Universiteit
}

Leiden

The Netherlands

\section{A review of dynamic models and stability analysis for a hydro-turbine governing system}

Xu, B.; Zhang, J.; Egusquiza, M.; Chen, D.; Li, F.; Behrens, P.A.; Egusquiza, E.

\section{Citation}

Xu, B., Zhang, J., Egusquiza, M., Chen, D., Li, F., Behrens, P. A., \& Egusquiza, E. (2021). A review of dynamic models and stability analysis for a hydro-turbine governing system. Renewable And Sustainable Energy Reviews, 144. doi:10.1016/j.rser.2021.110880

Version:

Publisher's Version

License:

Licensed under Article 25fa Copyright Act/Law (Amendment Taverne)

Downloaded from: https://hdl.handle.net/1887/3249402

Note: To cite this publication please use the final published version (if applicable). 


\title{
A review of dynamic models and stability analysis for a hydro-turbine governing system
}

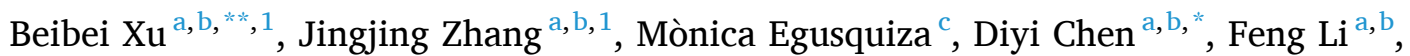 \\ Paul Behrens ${ }^{\text {d,e }}$, Eduard Egusquiza ${ }^{c}$ \\ ${ }^{a}$ Key Laboratory of Agricultural Soil and Water Engineering in Arid and Semiarid Areas, Ministry of Education, Northwest A\&F University, Shaanxi, Yangling, 712100, \\ PR China \\ ${ }^{\mathrm{b}}$ Institute of Water Resources and Hydropower Research, Northwest A\&F University, Shaanxi, Yangling, 712100, PR China

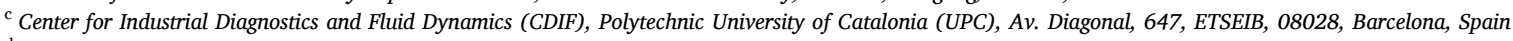 \\ ${ }^{\mathrm{d}}$ Leiden University College the Hague, Anna van Buerenplein 301, 2595 DG, The Hague, the Netherlands \\ ${ }^{\mathrm{e}}$ Institute of Environmental Sciences (CML), Leiden University, PO Box 9518, 2300 RA, Leiden, the Netherlands
}

\section{A R T I C L E I N F O}

\section{Keywords:}

Hydro-turbine governing system

Dynamic models

Stability analysis

Control method

Intermittent renewable energies

\begin{abstract}
A B S T R A C T
Hydropower offers highly flexible, low-carbon generation that can be used to balance electricity grids with high levels of wind and solar penetration. This will become increasingly important as the energy transition unfolds. However, hydropower generation faces several problems when used in a flexible, fast manner (on the order of seconds) when in part-load, overload, or transient conditions. Some of these issues may be addressed by an improved understanding of how the load is measured and controlled in a hydro-turbine governing system (HTGS). This paper reviews different subsystem models and stability analysis approaches for HTGS along with their applicability in different operational conditions and design layouts. The review revealed three main challenges facing the increasing flexible use of HTGS on the grid: 1) the combination of the HTGS and shaft model, 2) the control methods of HTGS with intermittent renewable energies, and 3) the uncertain nature of load on the overall performance and stability of the hydropower system. This review can stimulate further research on HTGS models and control methods to improve grid management.
\end{abstract}

\section{Introduction}

The wind-solar-hydro mix is already a complementary, low-carbon electricity-generating mix in several regions and offers considerable unexploited potential in many others [1]. As of 2018, total renewable electricity accounted for $25.6 \%$ of total global electricity, whereas wind-solar-hydro accounted for $88 \%$ of total renewable electricity (hydropower made up $15.9 \%$ of total global electricity generation, and wind-solar made up 6.7\%) [2]. As wind power and solar power are variable, they present challenges for the electricity grid when load matching $[3,4]$. Hydropower generation is well suited to load matching under fast variations as it can rapidly ramp up generation in a fast-response mode. The combination of wind and solar with fast-response hydropower generation offers a synergistic approach for managing the energy transition [5]. HTGS is the key component of hydropower generation, and a better understanding of HTGS under fast load matching offers the opportunity to improve the stability of the grid.

HTGS is a complex system that integrates the hydraulic, mechanical, and electrical subsystems (see Fig. 1) [7]. It is responsible for (1) performing the stable operation of units, as well as the mutual switching of various conditions; (2) ensuring the safe operation of the units and emergency shutdown in case of accidents; (3) optimizing the economic operation of the units (for example, distributing the electric load between units) [8]. In other words, the performance of HTGS is a matter of hydropower security, even power quality. Hence, research on HTGS inevitably attracts scholars' attention.

\subsection{Research status}

Recently, much research has been carried out on HTGS. Most of this

\footnotetext{
* Corresponding author. Institute of Water Resources and Hydropower Research, Northwest A\&F University, Shaanxi, Yangling, 712100, China.

** Corresponding author. Institute of Water Resources and Hydropower Research, Northwest A\&F University, Shaanxi, Yangling, 712100, China.

E-mail addresses: xubeibei0413@163.com (B.Xu), diyichen@nwsuaf.edu.cn (D. Chen).

1 These authors contribute equally to this paper.
} 
research focuses on three main aspects:

(1) Modeling: Modeling methods have been developed from modular modeling to unified modeling. The theories and methods for modular modeling are reasonably mature because of the rapid development of dynamic stability for each component. Unified modeling, where interactions between modules are characterized, has seen significant progress in recent years [9].

(2) Stability analysis: Stability analysis of HTGS is mainly carried out from the perspective of low-frequency oscillation [10] and the stability margin region [11]. The adopted theories from nonlinear dynamics, such as the Lyapunov theory [12] and bifurcation theory [13], are commonly used to achieve this analysis.

(3) Control Methods: Control methods are being improved from traditional control methods to artificial intelligence control methods to achieve a better power supply quality when HTGS is subjected to external disturbance. Traditional control methods, such as Proportional-Integral-Differential (PID) [14], have been widely used in HTGS. However, a lack of adaptability in dealing with the time delay of the guide vane and multiple conditions of HTGS promote the development of artificial intelligence control methods, such as fuzzy control (FC) [15] and fault-tolerant control (FTC) [16].

\subsection{Research gap}

The research gaps in modeling, stability analysis, and control methods are summarized as follows:

(1) Modeling: Most scholars pay attention to the single modular model or simplified unified model, both of which are unable to evaluate the potential flexibility of HTGS effectively in mitigating power variations from intermittent renewable energies. Specifically, the modular or simplified model, as summarized in Table 1, cannot obtain the same qualitative conclusion as a more complex model, resulting in unacceptable accidents. It is often difficult to reproduce accident characteristics because models generally lack sufficient accuracy in representing this complex system, such as the 2003 " $8.14^{\prime \prime}$ accident in the United States and Canada [17], and the 2006 "9.23" accident in Italy [18].

\subsection{Novel contributions}

It is necessary and urgent to evaluate the potential flexibility of Hydroelectric Generating Units (HGUs) with the rapid promotion of energy structure reformation. The dynamic model and stability analysis of HTGS are effective tools to assess the potential flexibility of HGUs to balance electricity grids with high levels of wind and solar penetration. Motivated by this reason, this review was conducted to provide an insight into possible solutions and development directions. The novel contributions of this review included: 1 ) the main achievements in the aspects of modeling, stability analysis, and control methods were summarized, and 2) three challenges and possible development directions for HTGS in mitigating power variations from intermittent renewable energies in the future were identified.

The rest of this paper is organized as follows. An overview of system configuration and stability analysis methods are discussed in Section 2. Section 3 provides an overview of the dynamic models used for different system components, where the characteristics and applicability of these models are also compared in detail. Stability analysis in published papers is presented in Section 4. Section 5 introduces several control methods and discusses the advantages and disadvantages of these methods. Section 6 overviews new challenges and possible development directions. Conclusions close this paper in Section 7.

\section{System configuration and stability analysis methods}

\subsection{System configuration}

The HTGS is composed of controlled and control systems. The regulating object contains the hydraulic system, the HGU, and the power grid. The control system includes the measuring, actuating, amplifying, and feedback elements. The operational elements of a typical HTGS are shown in Fig. 2. The governor adjusts the distributor of the hydroturbine according to the speed deviation of the HGU to balance the power between the HGU and power grid [38]. In general, the subsystem configuration of an HTGS depends on the location of the water source and the geography of the hydropower station. An example of a hydropower plant with an upstream surge tank is given in Fig. 3 [39].

\subsection{Stability analysis methods}

The stability of HTGS refers to the ability that it remains in an equilibrium state under normal conditions and regains an acceptable equilibrium state after being disturbed. Methods of stability analysis are divided into theoretical analysis [40], numerical simulation [38], and field experiment [41]. For the theoretical analysis, studies are performed using theories such as the Lyapunov theory and bifurcation theory. In terms of numerical simulation, various simulation models cope with the dynamic characteristics. Regarding the field experiment, it is conducted based on the prototype model of HTGS, while field experiments on this issue are relatively rare because the HGU is large-scale, important equipment of the hydropower plant. It is difficult to guarantee its safety, so some commissioning projects are destructive during the field experiment process [42]. Table 4 shows the research status of the stability analysis in published papers. From the above considerations, the commonly used stability analysis methods mainly concentrate on theoretical analysis and numerical simulation, as summarized in

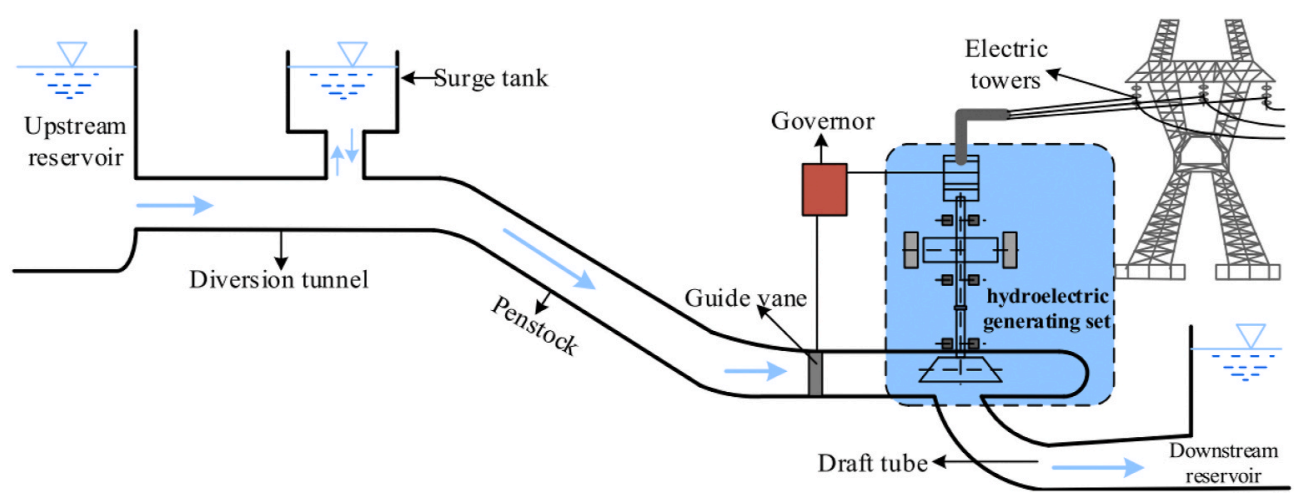

Fig. 1. The structure of a HTGS in a typical power system [6]. 
Table 1

Critical review summary of the modular model or simplified unified model in published literature.

(2) Stability analysis: The step power disturbance is generally used in theoretical analysis and numerical simulation to assess the stability of HTGS. However, the combination of the continuous power variation of intermittent renewable energies and the dead zone of HTGS make a greater difference in stability analysis than the step power disturbance, leading to difficulties in the potential flexibility evaluation of HTGS. This gap is summarized in Table 2.

\begin{tabular}{|c|c|c|c|c|c|c|c|c|c|c|c|}
\hline \multirow[t]{2}{*}{ Ref. } & \multicolumn{2}{|c|}{ Penstock } & \multicolumn{2}{|c|}{ Hydro-turbine } & \multicolumn{4}{|c|}{ Generator (Model order) } & \multirow{2}{*}{$\begin{array}{l}\text { Surge } \\
\text { tank }\end{array}$} & \multirow[t]{2}{*}{ Tail water } & \multirow[t]{2}{*}{ Shaft vibration } \\
\hline & Elastic & Rigid & Linear & Nonlinear & 1 & 2 & 3 & 5 & & & \\
\hline [19] & $\checkmark$ & $\times$ & $\times$ & $\times$ & $\times$ & $x$ & $\times$ & $\times$ & $\checkmark$ & $\times$ & $\times$ \\
\hline [20] & $\checkmark$ & $\times$ & $x$ & $\checkmark$ & $\checkmark$ & $x$ & $x$ & $x$ & $\checkmark$ & $x$ & $x$ \\
\hline [21] & $x$ & $\checkmark$ & $x$ & $\checkmark$ & $x$ & $x$ & $x$ & $x$ & $x$ & $\times$ & $x$ \\
\hline [22] & $x$ & $\times$ & $x$ & $\times$ & $x$ & $x$ & $\times$ & $\times$ & $\checkmark$ & $\times$ & $\times$ \\
\hline [23] & $x$ & $\checkmark$ & $x$ & $\checkmark$ & $x$ & $x$ & $x$ & $\times$ & $\checkmark$ & $\checkmark$ & $x$ \\
\hline [24] & $x$ & $\times$ & $x$ & $x$ & $x$ & $\checkmark$ & $\checkmark$ & $\checkmark$ & $x$ & $x$ & $x$ \\
\hline [25] & $x$ & $x$ & $x$ & $x$ & $x$ & $\times$ & $\times$ & $\checkmark$ & $x$ & $x$ & $\times$ \\
\hline [26] & $x$ & $x$ & $x$ & $x$ & $\checkmark$ & $\times$ & $x$ & $x$ & $x$ & $x$ & $x$ \\
\hline [27] & $\checkmark$ & $x$ & $\checkmark$ & $\times$ & $x$ & $\times$ & $\times$ & $\checkmark$ & $x$ & $\times$ & $x$ \\
\hline [28] & $\checkmark$ & $x$ & $x$ & $\checkmark$ & $\checkmark$ & $x$ & $x$ & $\times$ & $x$ & $\times$ & $x$ \\
\hline [29] & $\checkmark$ & $x$ & $x$ & $\checkmark$ & $x$ & $\checkmark$ & $\times$ & $x$ & $x$ & $x$ & $\times$ \\
\hline [30] & $\checkmark$ & $x$ & $x$ & $\checkmark$ & $x$ & $\times$ & $x$ & $\checkmark$ & $x$ & $x$ & $\checkmark$ \\
\hline [31] & $\checkmark$ & $x$ & $\checkmark$ & $x$ & $\times$ & $\checkmark$ & $x$ & $x$ & $x$ & $\times$ & $x$ \\
\hline [32] & $x$ & $x$ & $x$ & $\checkmark$ & $x$ & $x$ & $x$ & $\checkmark$ & $x$ & $x$ & $x$ \\
\hline
\end{tabular}

Table 2

Critical review summary of the stability analysis in published literature.

(3) Control methods: Control methods are developed based on traditional simplified models, but these models do not consider the effect of shaft vibration on the HTGS. Therefore, these methods are incapable of tracking all of the operational conditions, resulting in risks in power supply reliability. An illustration of this gap is summarized in Table 3 .

\begin{tabular}{lll}
\hline Ref. & Step power disturbance & Coupling with intermittent renewable energies \\
\hline$[6]$ & $\checkmark$ & $\times$ \\
{$[7]$} & $\checkmark$ & $\times$ \\
{$[33]$} & $\checkmark$ & $\times$ \\
{$[1]$} & $\checkmark$ & $\checkmark$ \\
{$[3]$} & $\times$ & $\checkmark$ \\
{$[5]$} & $\times$ & $\checkmark$ \\
\hline
\end{tabular}

Table 5. The processing flow charts of these methods are presented in Fig. 4.

Theoretical analysis and numerical simulation have the advantages of clear principles and concise physical meanings. However, some specific assumptions or simplifications (e.g., ignoring nonlinear factors and high-order components) need to be made using theoretical analysis and a numerical simulation, which may hide some dangerous phenomena that pose a threat to the stable and safe operation of the HTGS.

With the rapid implementation of energy-structure reformation, the requirements of the flexibility of HTGS change from the optimal operational region to the overall operational region. Therefore, it is an urgent and burning issue to combine a field experiment and numerical simulation/theoretical analysis to maintain the safety and stability of HTGS.

\section{Dynamic models of HTGS components}

\subsection{Models of the diversion system}

\subsubsection{Models of the surge tank}

Hydropower plants with long conduits may be subject to water hammer, which may threaten the system's stability. The classic solution is to introduce an upstream and/or downstream surge tank to minimize water hammer effects [19]. The surge tank, as a critical component of diversion-type hydropower plants [66], has an important function in reducing the amplitude of pressure fluctuations by reflecting the incoming pressure waves and both storing and providing water [20,21].

3.1.1.1. Layout of the surge tank. The surge tank is arranged in various forms, such as the upstream and/or downstream side of the powerhouse. Fig. 5 displays four typical layouts of the surge tank.

3.1.1.2. Models of the surge tank. The mathematical equation of a surge tank is [47]:

$\frac{d Q_{t}}{d t}=\frac{g A_{t}}{L}\left(H-z+f Q_{t}\left|Q_{t}\right|\right)$

where $Q_{t}$ is the flow; $A_{t}$ is the constant proportionality factor; $L$ is the length of the conduit; $f$ is the Darcy-Weisbach friction factor; and $g$ is the

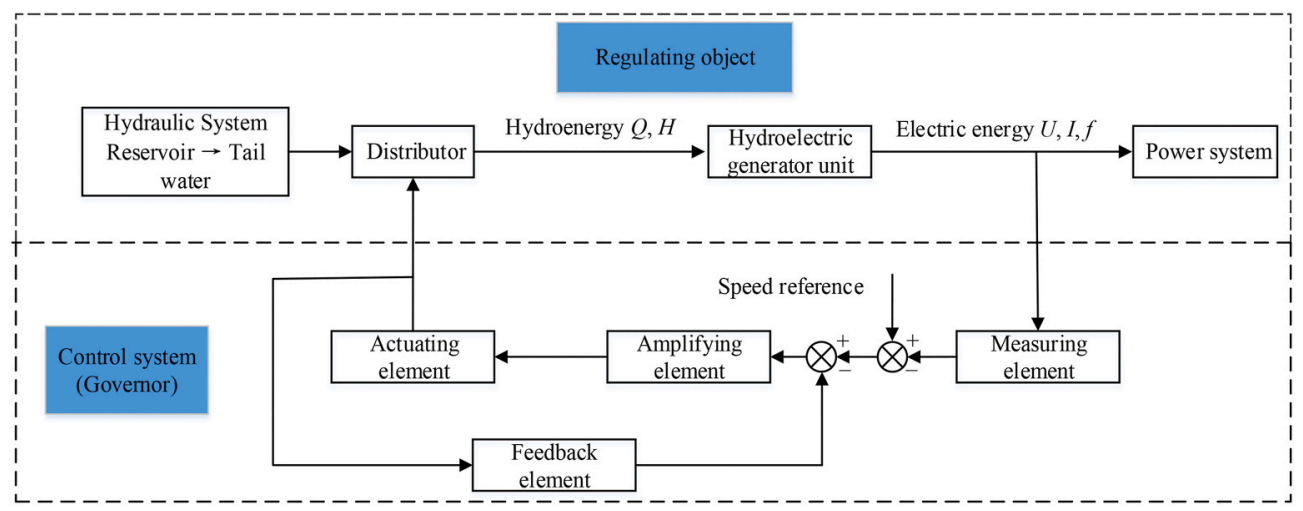

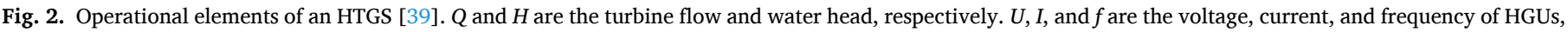
respectively. 
Table 3

Critical review summary of the control methods in published literature. FOPID denotes fractional-order PID control. SMC and PC are the sliding mode control and predictive control, respectively.

\begin{tabular}{|c|c|c|c|c|c|c|c|}
\hline \multirow[t]{2}{*}{ System } & \multirow[t]{2}{*}{ Ref. } & \multirow{2}{*}{$\begin{array}{l}\text { Traditional } \\
\text { PID }\end{array}$} & \multicolumn{5}{|c|}{ Modern control method } \\
\hline & & & FOPID & SMC & FC & FTC & PC \\
\hline \multirow[t]{7}{*}{ HTGS } & [1] & $\checkmark$ & $\checkmark$ & $\times$ & $\times$ & $\times$ & $\times$ \\
\hline & [2] & $\checkmark$ & $\checkmark$ & $\times$ & $\times$ & $x$ & $x$ \\
\hline & [12] & $\times$ & $\times$ & $\checkmark$ & $\times$ & $\checkmark$ & $\times$ \\
\hline & [34] & $\times$ & $\times$ & $\times$ & $\checkmark$ & $\times$ & $\checkmark$ \\
\hline & [35] & $\checkmark$ & $\checkmark$ & $x$ & $\times$ & $\times$ & $x$ \\
\hline & [36] & $\times$ & $\times$ & $\checkmark$ & $\checkmark$ & $\times$ & $\times$ \\
\hline & [37] & $\checkmark$ & $\times$ & $\times$ & $\checkmark$ & $\times$ & $\times$ \\
\hline \multirow{4}{*}{$\begin{array}{l}\text { HTGS+Shaft } \\
\text { system }\end{array}$} & [3] & $\checkmark$ & $\times$ & $x$ & $\times$ & $\times$ & $x$ \\
\hline & [4] & $\checkmark$ & $x$ & $x$ & $x$ & $x$ & $x$ \\
\hline & [5] & $\checkmark$ & $\times$ & $\times$ & $\times$ & $\times$ & $\times$ \\
\hline & [6] & $\checkmark$ & $\times$ & $\times$ & $\times$ & $\times$ & $\times$ \\
\hline
\end{tabular}

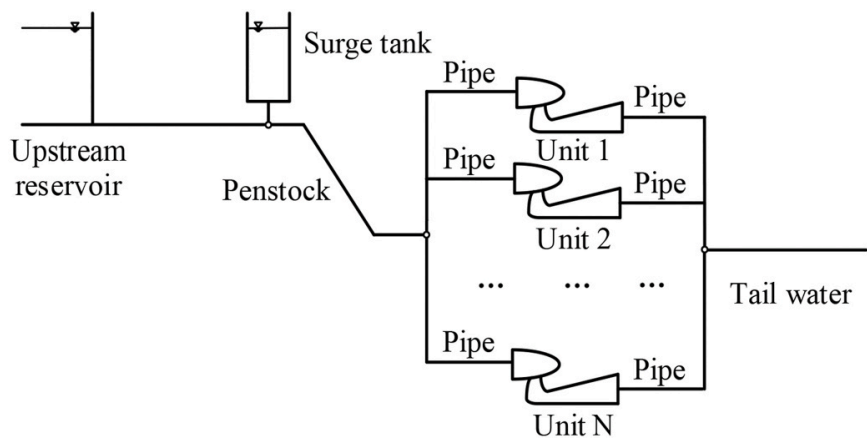

Fig. 3. Layout of a hydropower station with an upstream surge tank [33].

Table 4

Research status of stability analysis methods.

\begin{tabular}{cllll}
\hline Ref. & $\begin{array}{l}\text { Theoretical } \\
\text { analysis }\end{array}$ & $\begin{array}{l}\text { Numerical } \\
\text { simulation }\end{array}$ & $\begin{array}{l}\text { Field } \\
\text { experiment }\end{array}$ & $\begin{array}{l}\text { Lab } \\
\text { experiment }\end{array}$ \\
\hline$[43]$ & $\checkmark$ & $\times$ & $\times$ & $\times$ \\
{$[44]$} & $\times$ & $\checkmark$ & $\times$ & $\times$ \\
{$[45]$} & $\times$ & $\times$ & $\checkmark$ & $\times$ \\
{$[46]$} & $\times$ & $\checkmark$ & $\times$ & $\times$ \\
{$[47]$} & $\checkmark$ & $\times$ & $\times$ & $\times$ \\
{$[41]$} & $\checkmark$ & $\times$ & $\times$ & $\checkmark$ \\
{$[13]$} & $\checkmark$ & $\times$ & $\times$ & $\times$ \\
{$[19]$} & $\checkmark$ & $\checkmark$ & & $\times$ \\
\hline
\end{tabular}

gravitational acceleration.

The equation of continuity for the junction of the tunnel and the surge tank is:

$Q_{t}=Q_{s}+Q_{t u r}$

where $Q_{s}$ is the flow into the surge tank, and $Q_{s}=A_{s}(d \mathrm{z} / d t)$. $Q_{\text {tur }}$ is the turbine flow, and $A_{s}$ is the surge tank cross-sectional area. This gives:

$\frac{d z}{d t}=\frac{1}{A_{s}}\left(Q_{t}-Q_{t u r}\right)$

Equations (1) and (3) are the basic expressions that are suitable for both the upstream and downstream surge tanks. If the hydraulic losses of the surge tank orifice are neglected, normalizing Eq. (3), the transfer function between the flow and head is written as [55]:

$\frac{h_{s}}{q_{\mathrm{s}}}=T_{j} s$

where $h_{s}$ and $q_{s}$ represent the head and the flow of surge tank, and $T_{j}$ is the time constant of the surge tank.
Table 5

Characteristic review of commonly used methods for stability analysis.

- Bifurcation is a specific phenomenon of the nonlinear system, where the system changes from one behavior to another different one [51]. In the HTGS, bifurcation usually results in a continuous oscillation phenomenon of HGUs [52]. The theoretical basis for this approach was pioneered in a set of papers. Guo and Yang [53] studied the HTGS's performances using Hopf bifurcation, and they found that the bifurcation solutions' stability was altered by changing the nonlinear term. Liang et al. [54] proposed the HTGS model, where the surge tank is considered and then investigated for unstable oscillation using the bifurcation theory. Chen et al. [55] applied the bifurcation theory to an HTGS to visualize bifurcation diagrams and phase orbits.

- The Lyapunov theory uses the Lyapunov exponent to analyze and identify the local stability in the field of potential operational states, also known as small-range stability [56]. The positive and negative exponents indicate that the system is in chaotic and stable states, respectively [57]. An example framework for calculating the largest Lyapunov exponent is shown in Fig. 4 (b). Foundational literature includes: Deng et al. [58] utilized the maximal Lyapunov exponent to analyze the stochastic global stability of HGU. Yi et al. [34] demonstrated that global asymptotic stability of HTGS with the state feedback predictive controller was achieved using the Schur complements and discrete Lyapunov function. Su et al. [59] found chaotic attractors when the maximum Lyapunov exponents were greater than zero.

- The numerical simulation assesses system stability by analyzing the fluctuation state of the system output (i.e., convergence, divergence, or continuous oscillation). Commonly used visualization forms include the time domain diagram and phase trajectory diagram. Here, Guo et al. [60] studied the influence of PI parameters on the oscillation characteristics of HTGS using time-domain diagrams. Similarly, Li et al. [61] used a numerical simulation to investigate the operational characteristics of HGTS from the viewpoint of the multi-time scale. Zhang et al. [62] established a multi-time-scale HTGS model, and HTGS stability under different time scales was presented using the time-domain simulation. Xu et al. [63] proposed a novel fractional-order HTGS model and established the stable region law of the novel system based on the time domain simulation analysis.

\begin{tabular}{lll}
\hline Approaches & Characteristics & Ref. \\
\hline Bifurcation theory & $\begin{array}{l}\text { Advantages: Reflects the characteristic oscillation } \\
\text { of the system } \\
\text { Disadvantages: The calculation is complex, with a } \\
\text { higher equation order } \\
\text { Advantages: Suitable for both linear and nonlinear } \\
\text { systems } \\
\text { Lyapunov theory }\end{array}$ & {$[49]$} \\
Numerical & $\begin{array}{l}\text { Lyapunov functions } \\
\text { Advantages: The results are reproducible } \\
\text { simulation method }\end{array}$ & $\begin{array}{l}\text { Disadvantages: Different algorithmic approaches } \\
\text { might result in different characterizations. The } \\
\text { calculation time increases nonlinearly for high- } \\
\text { order systems }\end{array}$ \\
\hline
\end{tabular}

The transfer functions of the upstream and downstream surge tanks are described as follows: [68].

$\frac{h_{s 1}}{q_{1}-q_{t}}=\frac{1}{T_{j 1} s}$

$\frac{h_{s 2}}{q_{t}-q_{2}}=\frac{1}{T_{j 2} s}$

where $h_{s 1}$ and $h_{s 2}$ are the head of upstream and downstream surge tanks, respectively; $q_{t}$ is the flow of hydro-turbine; $T_{j 1}$ and $T_{j 2}$ represent the time constant of upstream/downstream surge tanks, respectively; and $q_{1}$ and $q_{2}$ are the flow of the upstream and tail race tunnel, respectively.

3.1.1.3. Appropriate configuration of the surge tank. A surge tank must be sized and placed thoughtfully in the larger hydropower system if excessive pressure or over-speeding is to be avoided. In a hydropower plant with a long conduit, the surge tank is generally larger in size and higher in cost. There is a vigorous academic debate about how this is best done. Table 6 shows some international regulations for the 


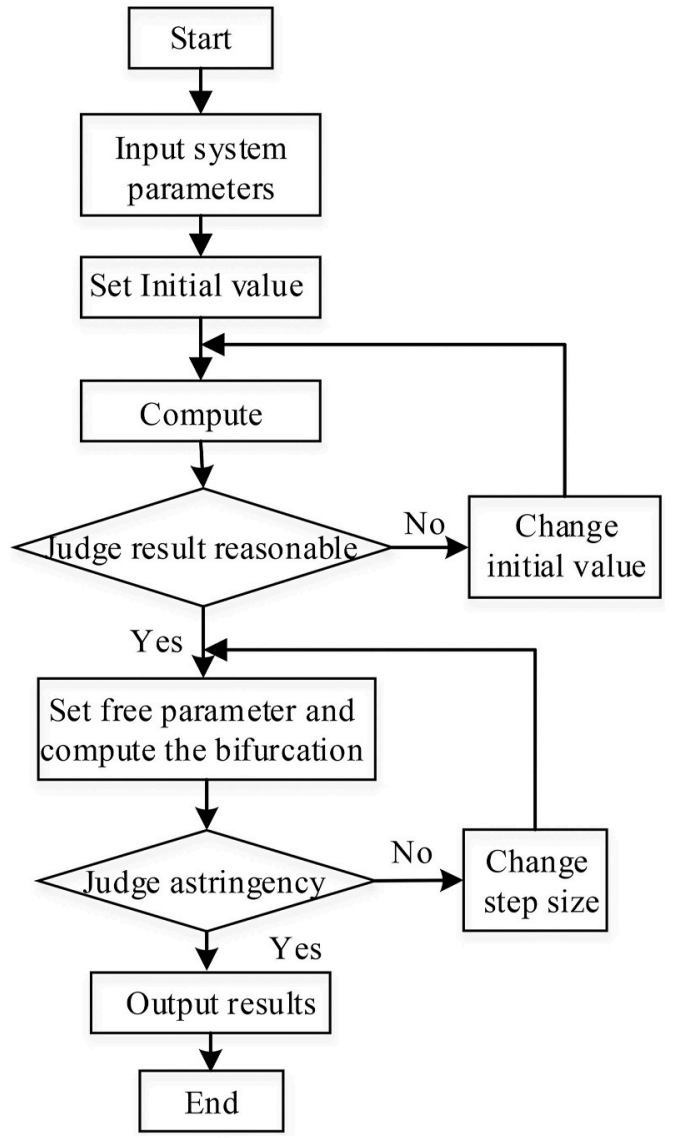

(a)

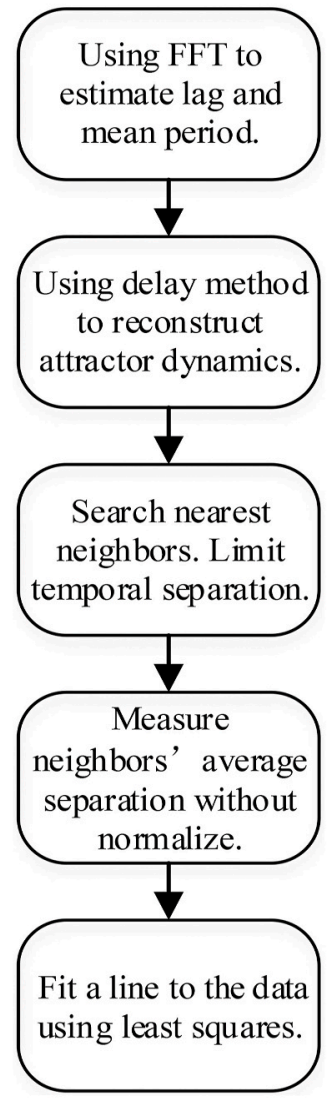

(b)

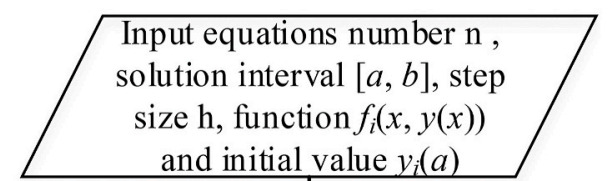

and initial value $v_{i}(a)$

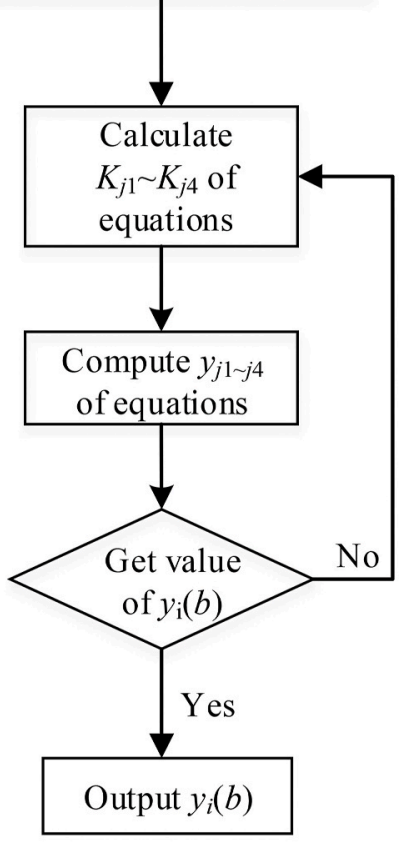

(c)

Fig. 4. Flow charts of the three stability analysis approaches. (a) Bifurcation theory [64]; (b) Lyapunov theory [57]; (c) Numerical simulation [65].

(a)
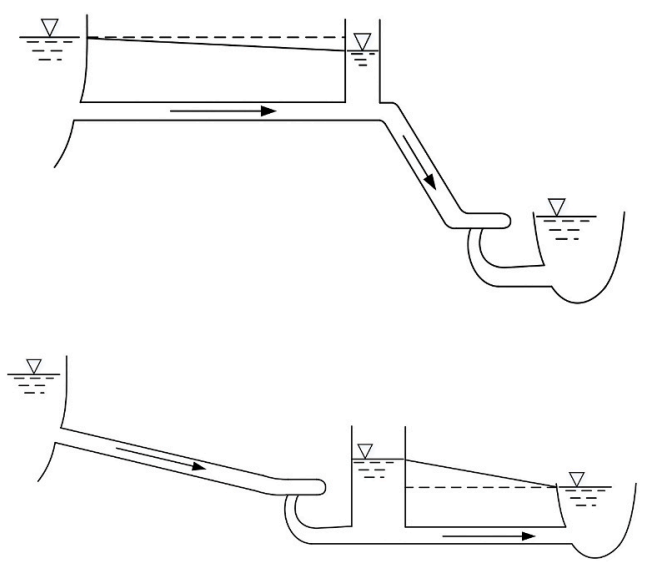

(c) (b)

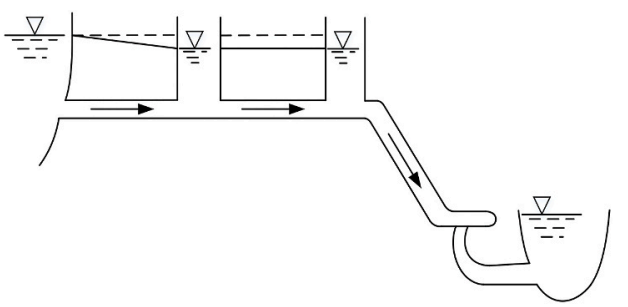

(d)

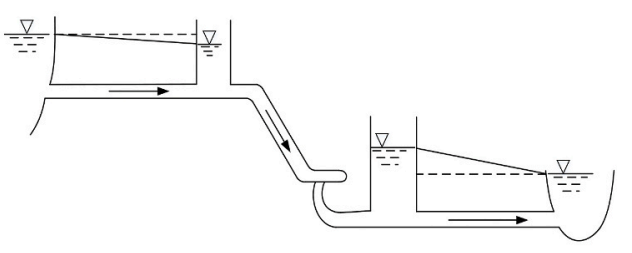

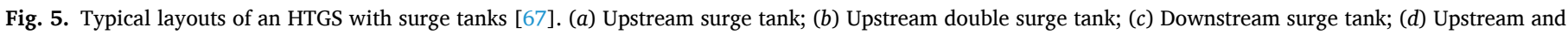
downstream double surge tanks.

configuration of surge tanks.

3.1.1.4. Applications of surge tank model. There have been several applications of a surge tank model. For example, France [74-77] focused on finite difference and finite element methods to study surge tank problems. Bao et al. [66] summarized the conditions for the configuration of surge tanks from the viewpoint of operational stability, regulation assurance, and regulation quality, which guide surge-tank setting. Fang et al. [78] established the HTGS model with a high water head and a long-distance penstock and then investigated the influence of surge-tank parameters on the dynamic performance of the HTGS. Vereide et al. [79] investigated the influence of the surge-tank throttle on the hydraulic transient and the results showed that the throttle enhances water hammer.

\subsubsection{Penstock models}

The penstock is subject to water hammer during water fluctuation, which brings an undesirable threat to the penstock (e.g., a broken-pipe 
Table 6

Regulations for the configuration of surge tanks.

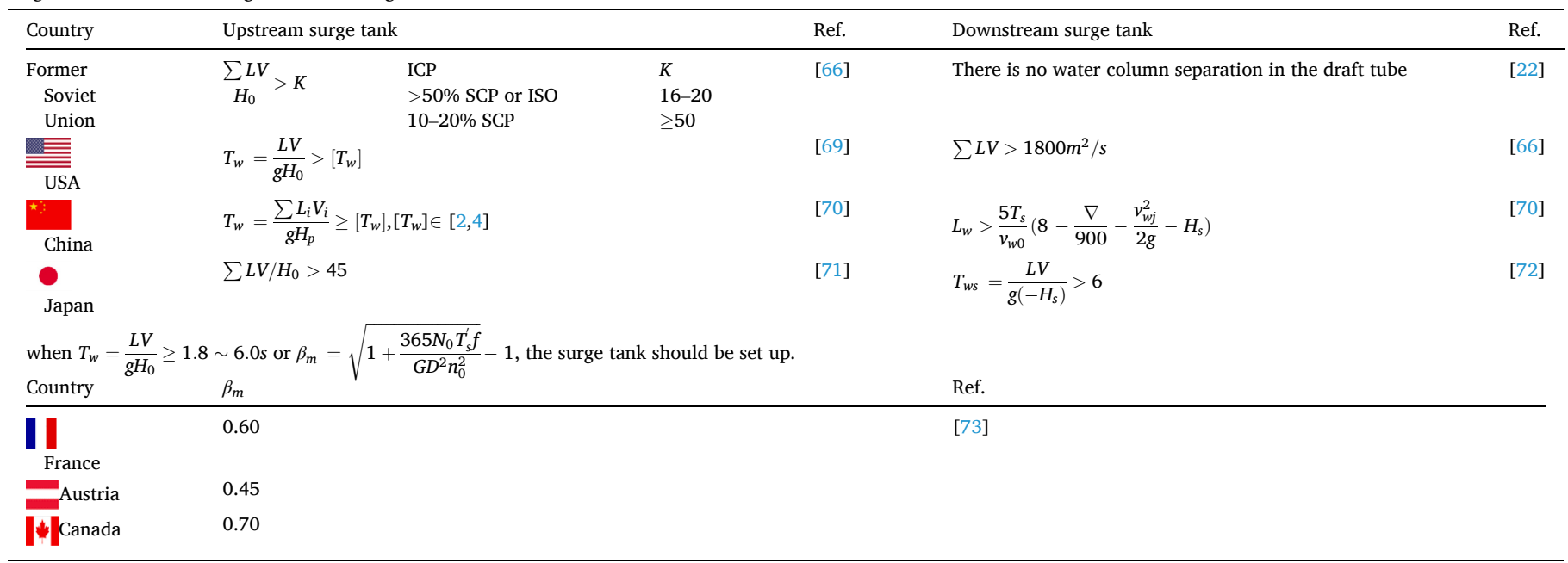

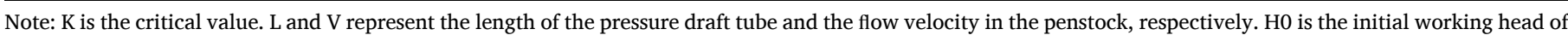

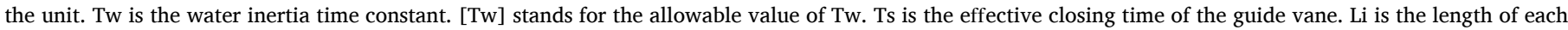

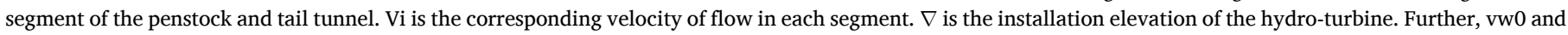

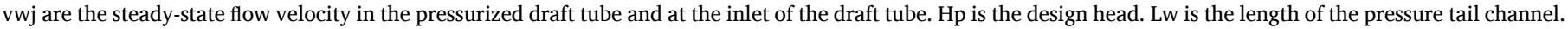

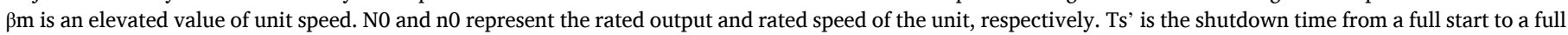

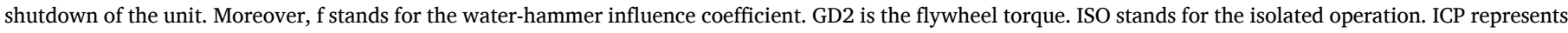
installed capacity. SCP is the system capacity. Hs is the minimum inundation depth, and Tws is the time constant of the draft tube.

accident). Hence, the transient modeling of the penstock to analyze the water hammer effect to eliminate hidden dangers is an indispensable task. The main calculation methods of water hammer include the analytic method, graphic method, and characteristic method, as shown in Table 7. At present, the analytic method and characteristic method are most widely used and verified.

3.1.2.1. Characteristic method. Wylie and Streeter first proposed the water hammer equation based on the characteristic method [83]. It transforms partial differential equations into ordinary differential equations by introducing a Lagrange factor and solves equations using boundary conditions.

The continuity and momentum equations used to describe the flow characteristic are given as $[10,84]$.

$$
\left\{\begin{array}{l}
\frac{\partial H}{\partial x}+\frac{1}{g} \frac{\partial v}{\partial x}+\frac{v}{g} \frac{\partial v}{\partial x}+\frac{f v|v|}{2 g D}=0 \\
\frac{\partial H}{\partial t}+v \frac{\partial H}{\partial x}+\frac{a^{2}}{g} \frac{\partial v}{\partial x}+v \sin \alpha=0
\end{array},\right.
$$

where $H, x$, and $v$ are the water head, the distance along the pipeline,

Table 7

\begin{tabular}{|c|c|c|}
\hline Methods & Characteristics & Ref. \\
\hline Analytic method & $\begin{array}{l}\text { Advantages: Concise physical meanings; simple } \\
\text { calculation procedure. } \\
\text { Disadvantages: Difficult to deal with the boundary } \\
\text { conditions of a complex piping system; lower } \\
\text { calculation accuracy }\end{array}$ & [80] \\
\hline Graphic method & $\begin{array}{l}\text { Advantages: Clear concept and simple calculation } \\
\text { procedure for simple pipe systems. } \\
\text { Disadvantages: Tedious drawing process and lower } \\
\text { calculation accuracy for a complex pipe system. }\end{array}$ & [81] \\
\hline $\begin{array}{l}\text { Characteristic } \\
\text { method }\end{array}$ & $\begin{array}{l}\text { Advantages: High precision; easy to deal with } \\
\text { complex boundary conditions. } \\
\text { Disadvantages: Needs to be corrected under the } \\
\text { condition of a Non-constant or non-equilibrium } \\
\text { Kurang number. }\end{array}$ & [82] \\
\hline
\end{tabular}

Numerical solutions of water hammer. and the flow victory, respectively; $g$ represents the acceleration of gravity; and $D, a$, and $\alpha$ represent the penstock diameter, wave speed of water hammer, and angle between the penstock and horizontal, respectively.

Transforming Eq. (7) into finite difference equations, one can get:

$\left\{\begin{array}{l}C^{+}: Q_{\mathrm{p}}=C_{p}-C_{a R} H_{p} \\ C^{-}: Q_{\mathrm{p}}=C_{n}+C_{a S} H_{p}\end{array}\right.$

where $P$ and $R$ represent two points of the penstock. $C_{P}, C_{n}, C_{a R}$, and $C_{a S}$ stand for intermediate variables. The expressions of these intermediate variables are:

$$
\begin{gathered}
C_{p}=Q_{R}+\frac{g F_{R}}{a_{R}} H_{R}-\frac{f_{R} \Delta x}{2 D_{R} F_{R} a_{R}} Q_{R}\left|Q_{R}\right|-\frac{Q_{R} \Delta x g}{a_{R}^{2}} \sin \alpha \\
C_{n}=Q_{s}-\frac{g F_{S}}{a_{S}} H_{S}-\frac{f_{S} \Delta x}{2 D_{S} F_{S} a_{S}} Q_{S}\left|Q_{S}\right|+\frac{Q_{S} \Delta x g}{a_{S}^{2}} \sin \alpha
\end{gathered}
$$

where $Q_{R}, Q_{S}, H_{R}$, and $H_{s}$ represent the flow and head at $R$ and $S$, respectively. $F_{R}$ and $F_{S}$ stand for the cross-sectional area at $R$ and $S$, respectively.

3.1.2.2. Analytic method. The Laplace transformation of the water hammer equation is carried out using the analytic method, and the expression of water hammer is solved in the frequency domain. The analytic expression of water hammer is then obtained by inverse Laplace transformation. Commonly used water hammer models are rigid and elastic models depending on the length of the penstock. Generally, the rigid model is used in the short-distance penstock, while the elastic model is an equally good choice for the long-distance penstock [55]. The advantages and disadvantages of the rigid and elastic models are shown in Table 8.

\subsection{Hydro-turbine models}

The hydro-turbine models are divided into linear and nonlinear models according to signal disturbance, as shown in Table 9. The current modeling methods are divided into two categories: the exterior characteristic method based on the exterior characteristic curve and the 
Table 8

Penstock models for the hydro-turbine governing system.

- Owing to its simplicity, the rigid model is widely used when the penstock is in a short/medium length. Guo et al. [23] analyzed the dynamic behaviors of HTGS by considering the rigid water column during primary frequency regulation. Zhang et al. [88] studied the dynamic responses of the HTGS with rigid water hammer when it was subjected to load rejection. Chen et al. [89] studied parameter identification in an HTGS where the rigid model was considered.

- The elastic water hammer effect cannot be ignored when the hydropower plant has a long penstock. In other words, the elastic model should be considered to describe its dynamic performances. Under this framework, Ling et al. [52] studied the bifurcation phenomena of the HTGS with an elastic water hammer model. Zeng et al. [46] derived the differential equation of elastic water column and then verified its applicability in describing transient impacts. Kishor et al. [44] performed the elastic model to investigate the power response in the time and frequency domains.

\begin{tabular}{|c|c|c|c|}
\hline Models & Equations & Characteristics & Ref. \\
\hline Rigid model & $G_{h}(s)=-T_{w} s$ & $\begin{array}{l}\text { Advantages: Simple calculation } \\
\text { and reasonable accuracy } \\
\text { Disadvantages: Modeling } \\
\text { inaccuracy when penstock } \\
\text { length is above } 200 \mathrm{~m}\end{array}$ & $\begin{array}{l}{[39,} \\
85]\end{array}$ \\
\hline $\begin{array}{l}\text { First-order } \\
\text { elastic } \\
\text { model }\end{array}$ & $\begin{array}{l}G_{h}(s)=- \\
2 h_{w} \tanh 0.5 T_{r} s\end{array}$ & $\begin{array}{l}\text { Advantages: Accurate modeling } \\
\text { of any penstock length } \\
\text { Disadvantages: Ignores the first } \\
\text { oscillation mode between the } \\
\text { mechanical and hydraulic } \\
\text { systems }\end{array}$ & [86] \\
\hline $\begin{array}{l}\text { Second- } \\
\text { order } \\
\text { elastic } \\
\text { model }\end{array}$ & $\begin{array}{l}G_{h}(s)=-T_{w} s /(1+ \\
\left.0.125 T_{r}^{2} s^{2}\right)\end{array}$ & $\begin{array}{l}\text { Advantages: Captures the } \\
\text { second oscillation mode of } \\
\text { hydro-mechanic-electric factors } \\
\text { Disadvantages: Complex } \\
\text { calculations }\end{array}$ & [87] \\
\hline $\begin{array}{l}\text { Third-order } \\
\text { elastic } \\
\text { model }\end{array}$ & $\begin{array}{l}G_{h}(s)=- \\
2 h_{w} \frac{T_{r}^{3} s^{3} / 48+T_{r} s / 2}{T_{r}^{2} s^{2} / 8+1}\end{array}$ & $\begin{array}{l}\text { Advantages: Higher oscillation } \\
\text { modes are captured } \\
\text { Disadvantages: (Even more) } \\
\text { complex calculations }\end{array}$ & [43] \\
\hline
\end{tabular}

internal character analysis, as shown in Table 10.

\subsubsection{Exterior characteristic method}

The exterior characteristic method describes the relation of the guide vane, head, flow, speed, torque, and other parameters based on the synthetic characteristic curve. In the modeling process, the hydroturbine model is expressed as a linear model near a specific operational point [78]:

$\left\{\begin{array}{l}m_{t}=e_{x} x+e_{y} y+e_{h} h \\ q=e_{q x} x+e_{q y} y+e_{q h} h\end{array}\right.$

Table 9

Hydro-turbine model classification.

\begin{tabular}{|c|c|c|c|}
\hline Models & Signal disturbances & Characteristics & Ref. \\
\hline $\begin{array}{l}\text { Linear } \\
\text { model }\end{array}$ & $\begin{array}{l}\text { Load disturbance } \\
< \pm 10 \% \text { rated value, } \\
\text { Frequency deviation } \\
< \pm 8 \% \text { rated value }\end{array}$ & $\begin{array}{l}\text { Advantages: Clear physical } \\
\text { meaning; simple structure; } \\
\text { convenient to analyze } \\
\text { stability in the frequency } \\
\text { domain using modern control } \\
\text { theory; convenient for the } \\
\text { optimal design of various } \\
\text { controllers. } \\
\text { Disadvantages: Can result in } \\
\text { errors due to simplifications. }\end{array}$ & $\begin{array}{l}{[13,14,} \\
52]\end{array}$ \\
\hline $\begin{array}{l}\text { Nonlinear } \\
\text { model }\end{array}$ & $\begin{array}{l}\text { Load disturbance }> \\
\pm 10 \% \text { rated value, } \\
\text { Frequency deviation }> \\
\pm 8 \% \text { rated value }\end{array}$ & $\begin{array}{l}\text { Advantages: Can capture } \\
\text { nonlinearities in HTGS } \\
\text { operation. } \\
\text { Disadvantages: May be } \\
\text { difficult to calculate because } \\
\text { of complexities in the } \\
\text { modeling. }\end{array}$ & $\begin{array}{l}\text { [52, } \\
90-92]\end{array}$ \\
\hline
\end{tabular}

Table 10

Numerical solution approaches for dynamic turbine torque.

\begin{tabular}{|c|c|c|}
\hline Methods & Characteristics & Ref. \\
\hline $\begin{array}{l}\text { Exterior } \\
\quad \text { characteristic }\end{array}$ & $\begin{array}{l}\text { Advantages: Accurate solution under transient } \\
\text { conditions } \\
\text { Disadvantages: Difficult to obtain the complete } \\
\text { characteristic curve; limited application }\end{array}$ & [93] \\
\hline $\begin{array}{l}\text { Internal } \\
\quad \text { characteristic }\end{array}$ & $\begin{array}{l}\text { Advantages: High accuracy } \\
\text { Disadvantages: Difficult to measure the parameters of } \\
\text { the hydro-turbine structure; the calculation very } \\
\text { complicated }\end{array}$ & [94] \\
\hline
\end{tabular}

where $e_{x}=\frac{\partial m_{t}}{\partial x}, \quad e_{y}=\frac{\partial m_{t}}{\partial y}, \quad e_{h}=\frac{\partial m_{t}}{\partial h}, \quad e_{q x}=\frac{\partial q}{\partial x}, \quad e_{q y}=\frac{\partial q}{\partial y}$, and $e_{q h}=\frac{\partial q}{\partial h}$ are the transfer coefficients of turbine torque and flow, respectively; and. $x$, $y, h, q$, and $m_{\mathrm{t}}$ are the relative deviations in speed, the guide-vane opening, head, flow, and torque, respectively.

Considering that the operational point changes frequently, variable transfer coefficients that vary with the speed and head are used to display the nonlinear properties of hydro-turbines [68]. To achieve this goal, Eq. (10) has been modified by some scholars. Several modified formulas have been proposed. For example, Shen [95] gave the nonlinear expressions of six transfer coefficients based on the comprehensive characteristic curve of the hydro-turbine as:

$$
\begin{array}{r}
e_{y}=e_{y m}(h+1) \\
e_{q y}=e_{q y m} \sqrt{h+1} \\
e_{x}=e_{x m} \sqrt{h+1} \\
e_{q x}=e_{q x m} \\
e_{h}=e_{h m} \\
e_{q h}=e_{q h m} \frac{1}{x+1}
\end{array}
$$

Thus Eq. (10) is rewritten as:

$$
\left\{\begin{array}{l}
m_{t}=e_{x m} \sqrt{h+1} x+e_{y m}(h+1) y+e_{h m} h \\
q=e_{q x m} x+e_{q y m} \sqrt{h+1} y+e_{q h m} \frac{1}{x+1} h
\end{array}\right.
$$

Li et al. [96] gave six nonlinear transfer coefficients of the HTGS under the condition of the load increasing (Fig. 6). Based on these transfer coefficient curves, the authors were able to describe the nonlinear dynamic behaviors. This is vital for maintaining stable operation under a sudden load increase.

The transfer coefficients' approximately calculated results in a nonnegligible accumulated error are shown in Fig. $7(a)$. To address this drawback, Zhang et al. [97] introduced the surface-cluster method to describe transfer coefficients in Fig. 7(b). The torque and flow at operational point $a$ are expressed as:

$$
\left\{\begin{array}{l}
m_{t d}\left(\begin{array}{lll}
x_{d} & y_{d} & h_{d}
\end{array}\right)=m_{t a}\left(\begin{array}{lll}
x_{a} & y_{a} & h_{a}
\end{array}\right)+\int_{x_{a}}^{x_{d}} e_{m x} d x+\int_{y_{a}}^{y_{d}} e_{m y} d y+\int_{h_{a}}^{h_{d}} e_{m h} d h \\
q_{t d}\left(\begin{array}{llll}
x_{d} & y_{d} & h_{d}
\end{array}\right)=q_{t a}\left(\begin{array}{lll}
x_{a} & y_{a} & h_{a}
\end{array}\right)+\int_{x_{a}}^{x_{d}} e_{q x} d x+\int_{y_{a}}^{y_{d}} e_{q y} d y+\int_{h_{a}}^{h_{d}} e_{q h} d h
\end{array}\right.
$$

The IEEE Group established a simplified nonlinear model that is popular with scholars. It is described as [98]:

$$
\begin{array}{r}
p_{m}=A_{t} h\left(q-q_{n 1}\right)-D_{t} y \Delta \omega \\
\frac{d q}{d t}=\frac{1-h-f_{p} q^{2}}{T_{w}} \\
q=y \sqrt{h}
\end{array}
$$

where $p_{m}$ is the hydro-turbine power; $A_{t}$ and $D_{t}$ are the proportionality and damping coefficient, respectively; $q_{n 1}$ represents the no-load flow of 


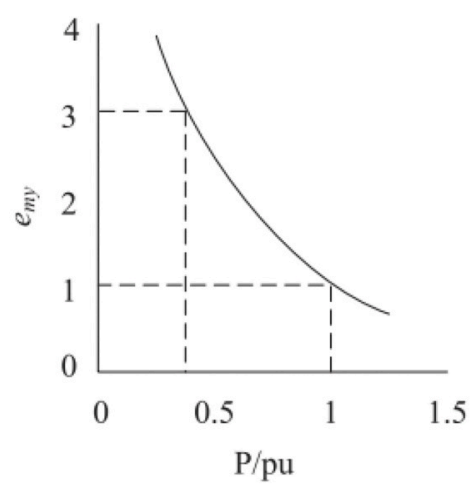

(a)

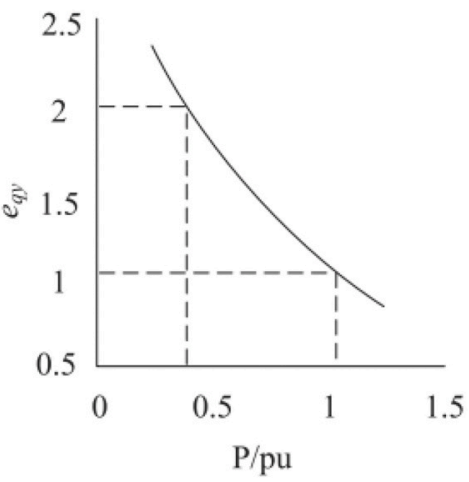

(d)

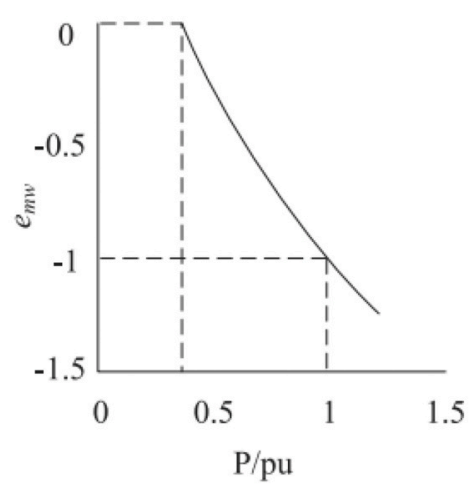

(b)

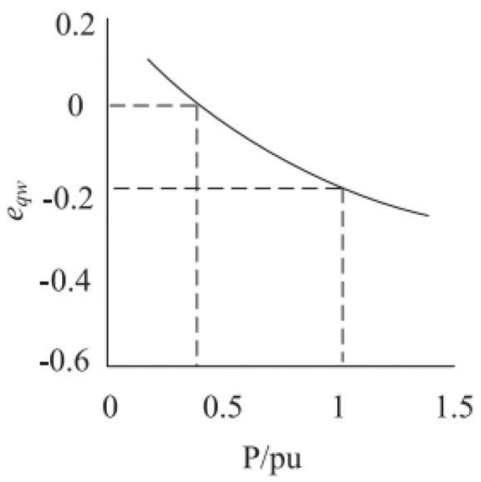

(e)

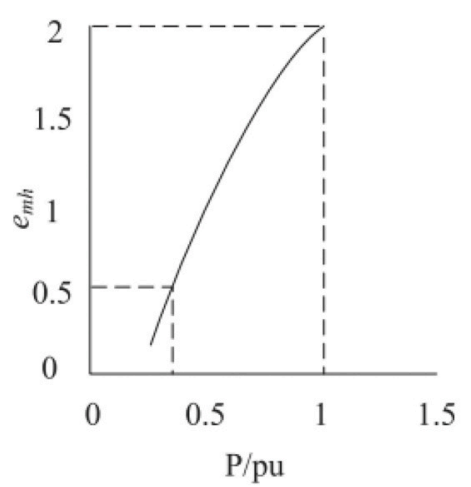

(c)

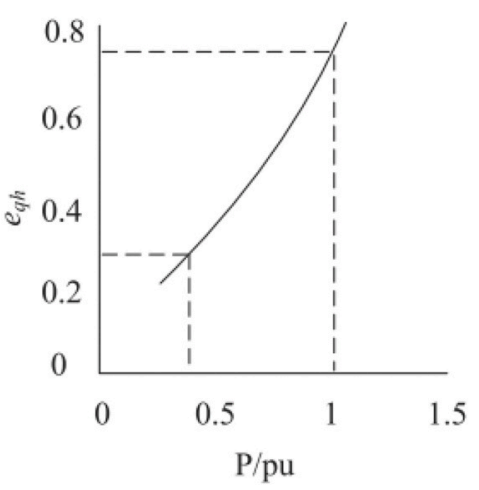

$(f)$

Fig. 6. Curves of transfer coefficients [96].

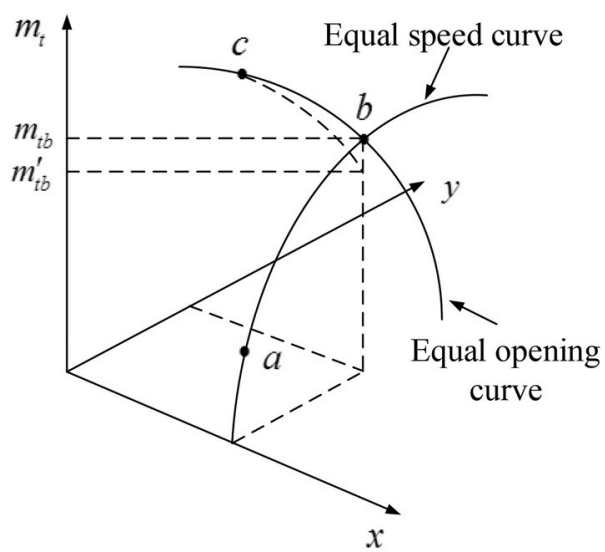

(a)

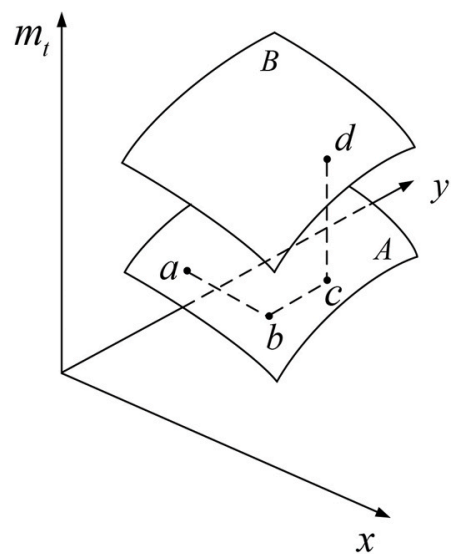

(b)

Fig. 7. The hydro-turbine torque curve [97]. (a) The accumulated errors in torque; (b) Surface-cluster method of torque.

the hydro-turbine; and $f_{p}$ is the water head loss coefficient.

The transfer coefficient varies with changes in operational conditions. More attention should be paid to the topic to describe the transfer coefficient in real time.

\subsubsection{Internal characteristic method}

The internal characteristic method is based on the geometric and structural parameters that obtain the nonlinear characteristics of the hydro-turbine. It takes the expression of head, flow, and torque as boundary conditions of the hydro-turbine. Hence, it has a clear physical meaning. Some assumptions need to be made in the modeling process, and the selection of parameters requires experience in transient calculation. Thus, the method is seldom used in engineering.

The flow and torque characteristics are given by Eq. (14). For more details, see Men and Nan [99]:

$\left\{\begin{array}{l}f_{1}=\left(y, n_{11}, Q_{11}\right)=0 \\ f_{2}=\left(y, n_{11}, M_{11}\right)=0\end{array}\right.$

where $Q_{11}$ and $M_{11}$ represent the unit flow and torque, respectively, and $n_{11}$ stands for unit speed.

To overcome the disadvantages of the exterior and internal characteristic methods, attention should be paid to combine the two methods to better deal with boundary issues. However, better, more relevant models have not yet been put forward. 


\subsection{Generator models}

The commonly used generator models are the first-order, secondorder, third-order, and fifth-order models [95], as shown in Table 11. For a detailed overview of this type of modeling, see Ref. [24]. For simplicity, the first-order model is usually used in the operational condition of a single machine. However, high-order models should be used when multiple units are in operation [100]. Regarding the application of generator models, Fang et al. [78] analyzed the hydraulic transient based on a first-order generator model. Xu et al. [101] studied the dynamic behaviors of HTGS under a shock load with a second-order generator. Sharafutdinov et al. [25] studied the stability of voltage and the rotor angle using the bifurcation theory in a third-order generator system. The lower the model order, the simpler the model that can be obtained, but the less accurate the results will be. However, the more complex the model, the harder the work becomes in both data requirements, computation time, and result interpretation [55].

\subsection{Governor models}

\subsubsection{Development course of the governor}

The development of the governor has three periods: the mechanical hydraulic governor, electric hydraulic governor, and microprocessorbased governor, as shown in Table 12. The earliest prime mover governor dates back to the centrifugal governor of the steam engine, invented by James Watt in 1782. Its operational principle is the same as that of the centrifugal governor. By the 1930s, the mechanical hydraulic governor had been refined following a Proportional-Integral (PI) approach. It is widely used in small- and medium-hydropower stations because of good static and dynamic characteristics. With the development of electronic controls, the first successful analog-electrical hydraulic governor appeared in the 1950s using PID regulation [39]. In the mid-1980s, microprocessor-based governors (in Fig. 8) saw rapid development [45].

The PI governor is expressed as [71,98]:

$G(s)=\frac{T_{d} s+1}{b_{t} T_{d} s}=\frac{1}{b_{t}}+\frac{1}{b_{t} T_{d} s}=k_{p}+\frac{k_{i}}{s}$

The PID controller is written as $[39,103]$.

$G_{r}(s)=\frac{Y(s)}{X(s)}=-\frac{K_{d} s^{2}+K_{p} s+K_{i}}{b_{p} K_{d} s^{2}+\left(b_{p} K_{p}+1\right) s+b_{p} K_{i}} \frac{1}{T_{y B} T_{y} s^{2}+T_{y} s+1}$

If assume $b_{p}=0$ and $T_{y}=0$, Eq. (17) can be rewritten as

$G(s)=K_{p}+\frac{K_{i}}{s}+K_{d} s$

where $K_{p}, K_{i}$ and $K_{d}$ are the proportional, integral, and differential gain, respectively; $b_{p}$ is the permanent droop; $T_{d}$ and $b_{t}$ are the buffer time constant and temporary droop, respectively; and $T_{y B}$ and $T_{y}$ are the time constant of the first-stage hydraulic amplification and the engager realtime constant, respectively.

\subsubsection{Application of the governor}

Many researchers have discussed the design and application of the governor. For example, Fang et al. [104] applied an improved particle swarm optimization to adjust PID gains and obtained better results in convergence and computational ability. Similarly, Jiang et al. [105] used an improved evolutionary programming method to optimize the online PID parameters, and the results showed that the proposed method had the advantages of a fast response and reduced overshooting. Cheng et al. [106] compared the difference between the intelligent PID and conventional PID, and the results showed that the former had a better dynamic performance. Li et al. applied several techniques, such as fault detection and self-recovery, to a microprocessor-based governor to improve its reliability [107].
Table 11

Different order generator models for HTGS.

\begin{tabular}{|c|c|c|c|}
\hline Models & Equations & Characteristics & Ref. \\
\hline $\begin{array}{l}\text { First } \\
\text { order }\end{array}$ & $\dot{\omega}=\frac{1}{T_{a b}}\left(m_{t}-m_{g 0}-e_{n} \omega\right)$ & $\begin{array}{l}\text { Advantages: Simple } \\
\text { calculation } \\
\text { Disadvantages: } \\
\text { Modeling inaccuracy, } \\
\text { especially for transient } \\
\text { processes } \\
\text { Applications: Only } \\
\text { considers the moment } \\
\text { of inertia of the } \\
\text { generator }\end{array}$ & [26] \\
\hline $\begin{array}{l}\text { Second } \\
\text { order }\end{array}$ & $\left\{\begin{array}{r}\dot{\delta}=\omega-1 \\
\dot{\omega}=\frac{1}{T_{a b}}\left[T_{m}-T_{e}-D_{t}(\omega-1)\right]\end{array}\right.$ & $\begin{array}{l}\text { Advantages: Results } \\
\text { are positive for the slow } \\
\text { response excitation } \\
\text { system } \\
\text { Disadvantages: } \\
\text { Transient electric } \\
\text { potential remains } \\
\text { unchanged } \\
\text { Applications: } \\
\text { Considers the moment } \\
\text { of inertia of the } \\
\text { generator, output } \\
\text { power, and power angle }\end{array}$ & $\begin{array}{l}{[24,} \\
95]\end{array}$ \\
\hline $\begin{array}{l}\text { Third } \\
\text { order }\end{array}$ & $\begin{array}{r}E_{q}^{\prime}=\frac{1}{T_{d 0}^{\prime}}\left[E_{f}-E_{q}^{\prime}-\left(X_{d}-X_{d}^{\prime}\right) i_{d}\right] \\
\left\{\dot{\omega}=\frac{1}{T_{a b}}\left[T_{m}-E_{q}^{\prime} i_{q}+\left(X_{d}^{\prime}-X_{q}\right) i_{d} i_{q}\right]\right. \\
\dot{\delta}=\omega-1\end{array}$ & $\begin{array}{l}\text { Advantages: Simple } \\
\text { structure and considers } \\
\text { the dynamics of the } \\
\text { excitation system } \\
\text { Disadvantages: } \\
\text { Complex calculation } \\
\text { Applications: } \\
\text { Considers the moment } \\
\text { of inertia of the } \\
\text { generator, output } \\
\text { power, power angle, } \\
\text { and the excitation } \\
\text { system }\end{array}$ & $\begin{array}{l}{[24,} \\
95]\end{array}$ \\
\hline $\begin{array}{l}\text { Fifth } \\
\text { order }\end{array}$ & $\begin{array}{r}E_{q}^{\prime}=\frac{1}{T_{d 0}^{\prime}}\left[E_{f}-E_{q}\right] \\
E_{q}^{\prime \prime}=\frac{1}{T_{d 0}^{\prime \prime}}\left[X_{r} T_{d 0}^{\prime \prime} E_{q}^{\prime}-E_{q}^{\prime \prime}+E_{q}^{\prime}-X i_{d}\right] \\
\left\{\quad E_{d}^{\prime \prime}=\frac{1}{T v_{q 0}^{\prime \prime}}\left[-E_{d}^{\prime \prime}+\left(X_{q}-X_{q}^{\prime \prime}\right) i_{q}\right]\right. \\
\dot{\omega}=\frac{1}{T_{a b}}\left[T_{m}-T_{e}-D_{t}(\omega-1)\right] \\
\dot{\delta}=\omega-1\end{array}$ & $\begin{array}{l}\text { Advantages: Accurate } \\
\text { modeling of transient } \\
\text { processes } \\
\text { Disadvantages: The } \\
\text { calculation is complex } \\
\text { Applications: } \\
\text { Considers the moment } \\
\text { of inertia of the } \\
\text { generator, output } \\
\text { power, power angle, } \\
\text { excitation system, and } \\
\text { super-transient } \\
\text { electromotive force of } \\
\text { the } d q \text {-axes }\end{array}$ & $\begin{array}{l}{[24,} \\
95]\end{array}$ \\
\hline
\end{tabular}

Note: $E_{q}=\frac{X_{d}-X_{1}}{X_{d}^{\prime}-X_{1}} E_{q}^{\prime}+\frac{X_{d}-X_{d}^{\prime}}{X_{d}^{\prime}-X_{1}} E_{q}^{\prime \prime}-\frac{\left(X_{d}-X_{d}^{\prime}\right)\left(X_{d}^{\prime \prime}-X_{1}\right)}{X_{d}^{\prime}-X_{1}} i_{d} ; T_{e}=\left[E_{q}^{\prime \prime} i_{q}+E_{d}^{\prime \prime} i_{d}-\right.$ $\left.\left(X_{d}^{\prime \prime}-X_{q}^{\prime \prime}\right)\right] i_{d} i_{q} ; X_{r}=\frac{X_{d}^{\prime \prime}-X_{1}}{X_{d}^{\prime}-X_{1}} ; X=X_{d}^{\prime}-X_{d}^{\prime \prime}$.

where $\omega$ and $\delta$ are the angular speed of the generator and rotor angle, respectively; $e_{n}$ is the accommodation coefficient; $m_{g 0}$ is the load disturbance of the generator; $m_{t}$ is the output torque of the hydro-turbine; $T_{a b}$ is the mechanical starting time; $T_{m}$ and $T_{e}$ are the electromagnetic power of the generator and the electromagnetic torque of the generator, respectively; $E_{q}$ ' and $E_{f}$ are the armature transient voltage of the $q$-axis and excitation voltage of the generator, respectively; $X_{d}$ and $X_{q}$ represent the $d q$-axes reactance; $X_{d}{ }^{\prime}$ is the $d$-axis transient reactance; $i_{d}$ and $i_{q}$ are the stator current of the $d$-axis and $q$-axis, respectively. Moreover, $T_{d o}$ ' and $T_{d o} o^{\prime \prime}$ denote the open-circuit transient and switching subtransient time constant of the $d$-axis, respectively. $E_{q}$ "' and $E_{d}$ "' represent the subtransient electromotive force of the $d q$-axes. $X_{d}$ ", and $X_{q}$ "' represent the subtransient reactance of the $d q$-axes. $X_{1}$ is the stator $q$-axis with winding leakage reactance, and $E_{q}$ is the no-load terminal transient electromotive force. 
Table 12

Comparisons of different governors.

\begin{tabular}{|c|c|c|c|}
\hline Types & Regulation law & Characteristics & Ref. \\
\hline $\begin{array}{r}\text { Mechanical } \\
\text { hydraulic }\end{array}$ & PI & $\begin{array}{l}\text { Advantages: Good static and } \\
\text { dynamic characteristics } \\
\text { Disadvantages: Low } \\
\text { sensitivity; poor automation. }\end{array}$ & [9] \\
\hline $\begin{array}{l}\text { Electric } \\
\text { hydraulic }\end{array}$ & PID & $\begin{array}{l}\text { Advantages: Simple structure, } \\
\text { faster speed response } \\
\text { Disadvantages: Excessive } \\
\text { oscillation in interconnected } \\
\text { systems; does not guarantee a } \\
\text { stable closed-loop system for at } \\
\text { all operational conditions }\end{array}$ & [14] \\
\hline $\begin{array}{l}\text { Microprocessor- } \\
\text { based }\end{array}$ & $\begin{array}{l}\text { PI, PID, or more } \\
\text { complex } \\
\text { regulation laws }\end{array}$ & $\begin{array}{l}\text { Advantages: Good reliability, } \\
\text { redundancy, flexibility, } \\
\text { improved performance, and } \\
\text { reliability } \\
\text { Disadvantages: Under special } \\
\text { circumstances, it may cause } \\
\text { overspeed and overvoltage } \\
\text { protection of the unit, resulting } \\
\text { in accidental shutdown. }\end{array}$ & $\begin{array}{l}{[45,} \\
102]\end{array}$ \\
\hline
\end{tabular}

Although traditional governors have been widely used in hydropower stations, they are incapable of achieving optimal control performance in all operational states, especially in transient conditions. To improve regulation quality, more advanced governors using intelligent control methods have been developed. These will be described in Section 5 .

\subsection{HTGS models}

Components of the HTGS exhibit strong nonlinearity, such as the hydro-turbine and governor [108,109], and many uncertain factors exist in structural parameters because of equipment aging and unit vibrations [33]. Modeling HTGS is, therefore, an important and difficult task. Different layouts of the hydropower plant can lead to different expressions of the system model, such as the HTGS model with or without the surge tank. Fig. 9 displays the canonical system model that considers different operational conditions. In general, the HTGS model is the coupling of modular models, which can be divided into linear and nonlinear models. The linear model is widely used in small disturbance conditions, while the nonlinear model is suitable for large disturbance conditions.

Scholars established the HTGS model to study various dynamic phenomena. Most of these studies were implemented under the integerorder framework. For instance, Liu and Liu [110] demonstrated the dynamic stability of a hydropower station with a linear turbine model under steady conditions. Related studies indicated that fluid has the property of memory. However, the integer order calculus has limitations in this respect because HTGS is a complex system with a non-minimum

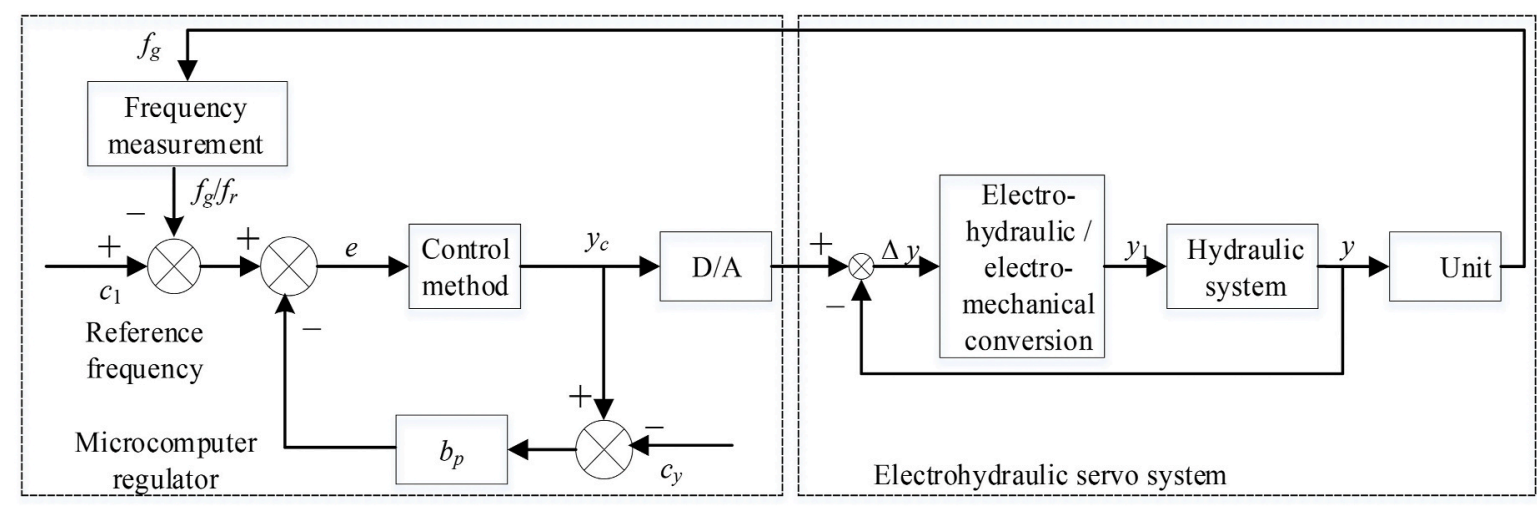

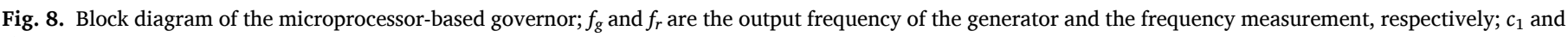

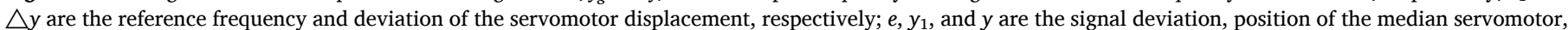
and primary servomotor, respectively.

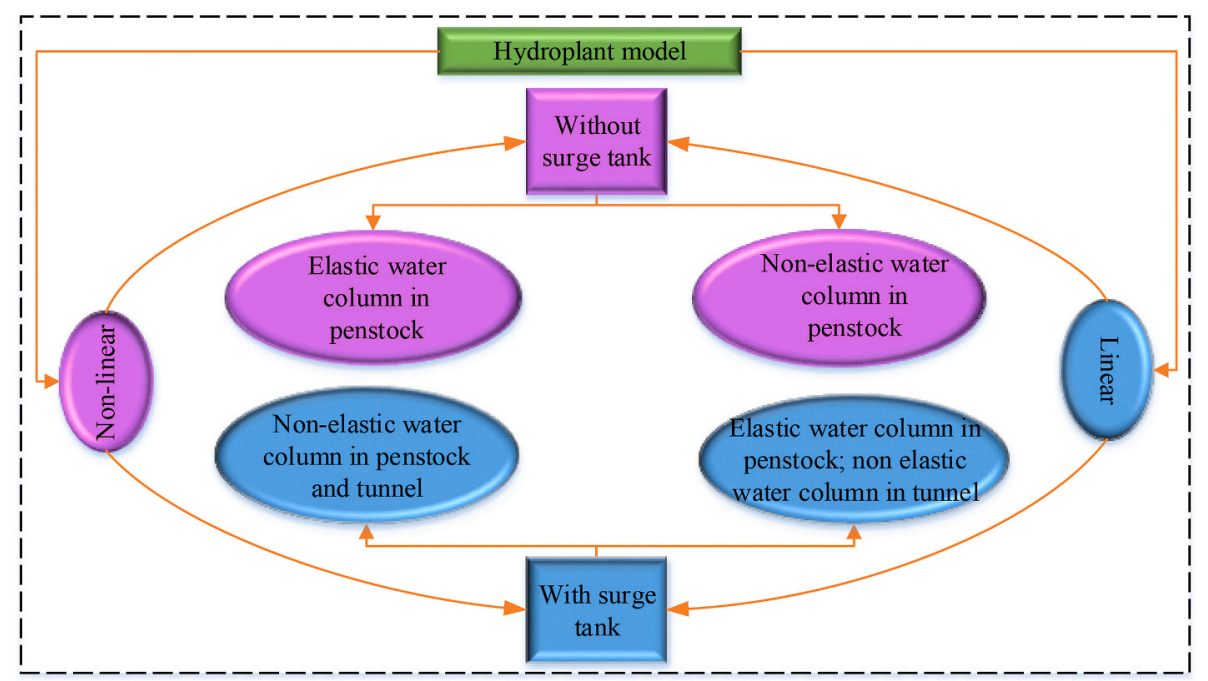

Fig. 9. Overview of the HTGS model [14]. 
phase and time variance. Fractional order calculus has the advantages of memory and strong dependence. Hence, to overcome the drawbacks of the integer order calculus, it is necessary to build a fractional-order mathematical model. Xu et al. [63] introduced the fractional-order theory (Eq. (19)) to analyze the dynamic performance of the HTGS, and then investigated the variable law of the $K_{p}-K_{d}$ stable region when the fractional order changed.

$$
\begin{gathered}
D^{q} x_{1}=x_{2} \\
D^{q} x_{2}=x_{3} \\
D^{q} x_{3}=-a_{0} x_{1}-a_{1} x_{2}-a_{2} x_{3}+y \\
D^{q} \delta=\omega_{0} \omega \\
D^{q} \omega=\frac{1}{T_{a b}}\left[m_{t}-\frac{E_{q}^{\prime} V_{s}}{X_{d}^{\prime}} \sin \delta-\frac{V_{s}^{2}}{2} \frac{X_{d}^{\prime}-X_{q}}{X_{d}^{\prime} X_{q}} \sin 2 \delta-D_{t} \omega\right] \\
D^{q} y=\frac{1}{T_{y}}\left(-k_{p}(r-\omega)-\frac{k_{i}}{\omega_{0}} \delta-k_{d} D_{t}^{q} \omega-y\right)
\end{gathered}
$$

where $x_{1}, x_{2}$, and $x_{3}$ are the state variables of the penstock system; $\omega_{0}$ is the rated speed of the generator; $a_{0}, a_{1}$, and $a_{2}$ are the intermediate variables related to transfer coefficients; and $V_{s}$ is the voltage of infinite power system.

In general, the HTGS regulates hydro-turbine speed to provide stable power to the grid without considering shaft vibration. Nevertheless, the shaft system model controls the vibration performance instead of the speed. In fact, HTGS and the shaft system model interact with each other. Unfortunately, related studies on the unified model have been rare. Hence, this is a hot issue to couple these two models to better understand the properties of a hydropower plant.

\section{Stability analysis}

As the key to the functioning of a hydropower plant, the HTGS's stability has considerable influence on the power system. Hence, it is an essential task to study the stability of the HTGS. For example, Yang et al. [111] studied the oscillation characteristics of HTGS under small disturbance, where the distribution of the smallest ratio with hydraulic-mechanical parameters changing is shown in Fig. 10. A larger value of water inertia $\left(T_{w}\right)$ results in a smaller damping ratio, meaning that HTGS is more stable. When the water column elasticity $\left(T_{e}\right)$ is approximately equal to 0.4 , a smaller damping ratio occurs. Although the influence of $T_{w}$ is not monotonic, a larger value of $T_{w}$ leads to the system more stable in general.
Pérez-Díaz et al. [29] presented the influence of the hydraulic short-circuit on the load-frequency regulation. Fig. 11 shows the frequency oscillation when the plant was subject to $65 \mathrm{MW}$ loss in a different initial situation. The frequency fluctuation diminished significantly with the number of pump units or Pelton increased because system inertia increases as the number of units increases. Also, shutting down or starting up one pump unit or Pelton was capable of supplying secondary load-frequency regulation, significantly reducing the time for frequency recovery to $50 \mathrm{~Hz}$.

$\mathrm{Xu}$ et al. [11] established a fractional order mathematical model of a hydro-turbine governing system, and an universal solution method is proposed about two parameters in a higher-degree equations acorroding to the fractional order stability theorem. Using this method, the stable region of the parameters $\mathrm{kd}$ and $\mathrm{kp}$ are investigated with the increase of fractional order and water hammer effect, as shown in Fig. 12.

Yu et al. [20] presented the stability of the HTGS during a small load disturbance process, namely a $-5 \%$ rated load. The authors simulated the stable region of an interconnected plant (B) and isolated the plant (A), as shown in Fig. 13. The results showed that the stable region and the regulation quality in an isolated condition were poor compared with those in an interconnected condition. In other words, the system stability was enhanced in the interconnected condition.

Similarly, Yang et al. [41] revealed ultra-low frequency oscillations using an experimental investigation and theoretical analysis. The system stability region based on the Routh-Hurwitz stability condition is shown in Fig. 14. If $K_{p}$ and $K_{i}$ were in the stability region, the system was stable from the viewpoint of the theoretical perspective. The system was unstable when parameters were in the unstable zone. Moreover, the

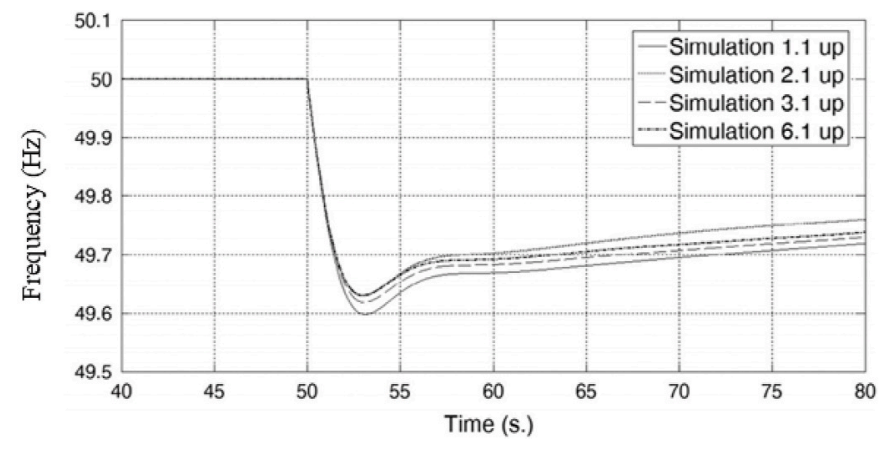

Fig. 11. Frequency deviation after the sudden loss of $65 \mathrm{MW}$ of generation in different cases [29].

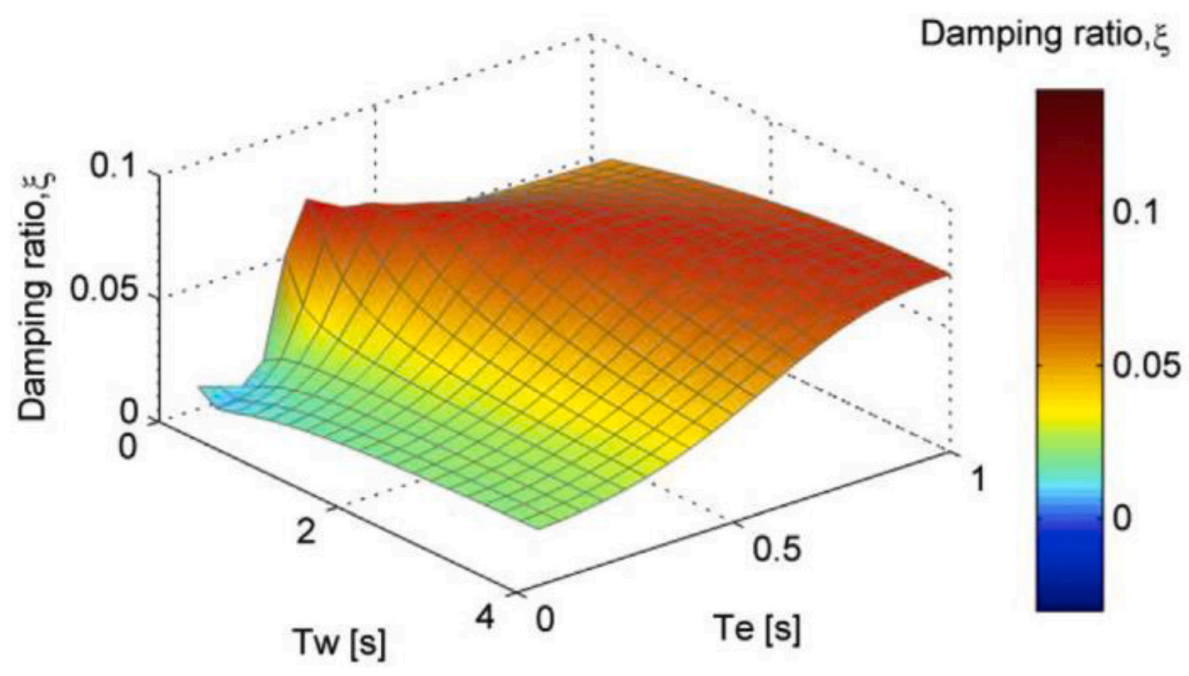

Fig. 10. The smallest ratio of the oscillation modes under open feedback [111]. 


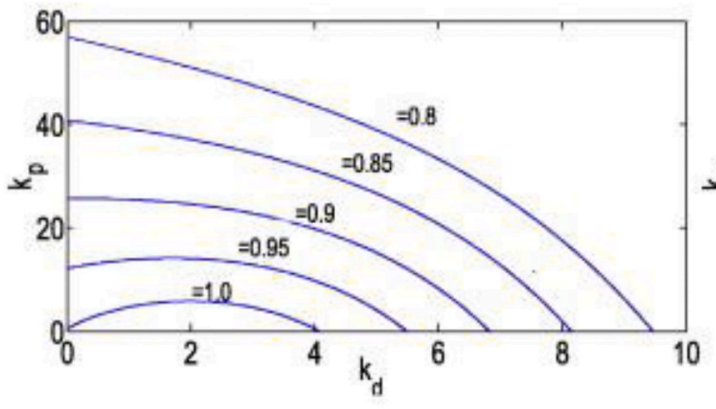

(a) $T_{r}=1.0$

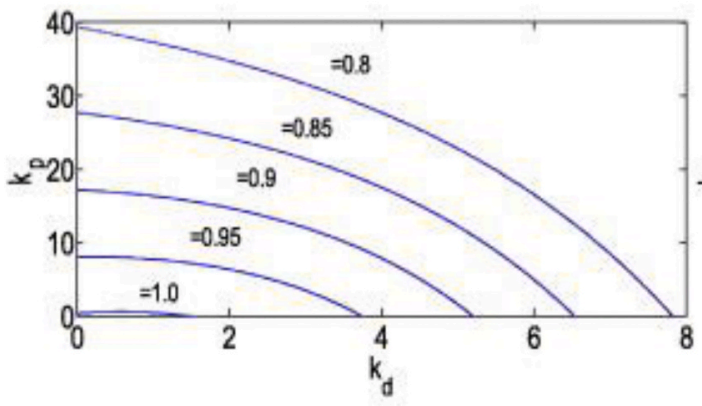

(c) $T_{r}=1.5$

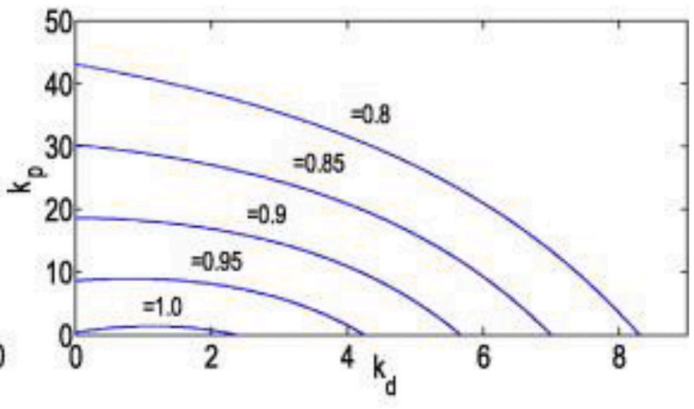

(b) $T_{r}=1.3$

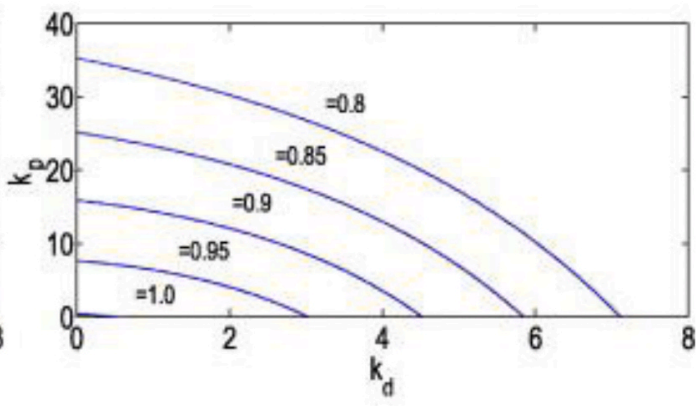

(d) $T_{r}=2.0$

Fig. 12. The stable region of $k_{d}-k_{p}$ of different $T_{r}$ for the hydro-turbine governing system with different fractional order.

attenuation of the oscillations increased as the stability margin increased.

Mercier et al. [112] proposed two different control methods to study power system stability. One uses electromagnetic torque to control power directly; the other uses rotational speed to control power indirectly. The simulation results under the two control methods are shown in Fig. 15. As Fig. 15(a) shows, the speed collapse occurred at $t=25 \mathrm{~s}$ because of a power increase, and the system lost stability. As Fig. 15(b) shows, the speed collapse phenomenon was avoided using rotational speed to control power. This is because the flow had enough time to adjust, thus ensuring system stability.

Guo et al. [60] investigated the operational characteristics of an HTGS with a surge tank using the Hopf bifurcation theory. The stable domain distribution is plotted in Fig. $16(a) . S_{1}, S_{3}$, and $S_{6}$ represent different operational states and were selected to simulate the phase space trajectories in detail, as shown in Fig. 16(b)-(d). Finally, the authors concluded that $K_{p}$ and $K_{i}$ should avoid specific bifurcation points to improve system stability.

\section{Control methods}

To maintain the quality and reliability of the electricity supply, a governor is used to control the generator speed in order to achieve the objective. This is usually conducted by a governor through a certain control strategy that mainly includes offline control (i.e., offline predecisions and real-time matching), online quasi-real-time control, and online real-time control [113]. The offline control needs massive calculations because many factors of system structure, power flow mode, and the fault situation should be considered, leading to a poor ability to adapt to the change in the power grid operational mode. For online quasi-real-time control, the controller collects the operational condition and analyzes expected accidents regularly. It can adapt to changes in the

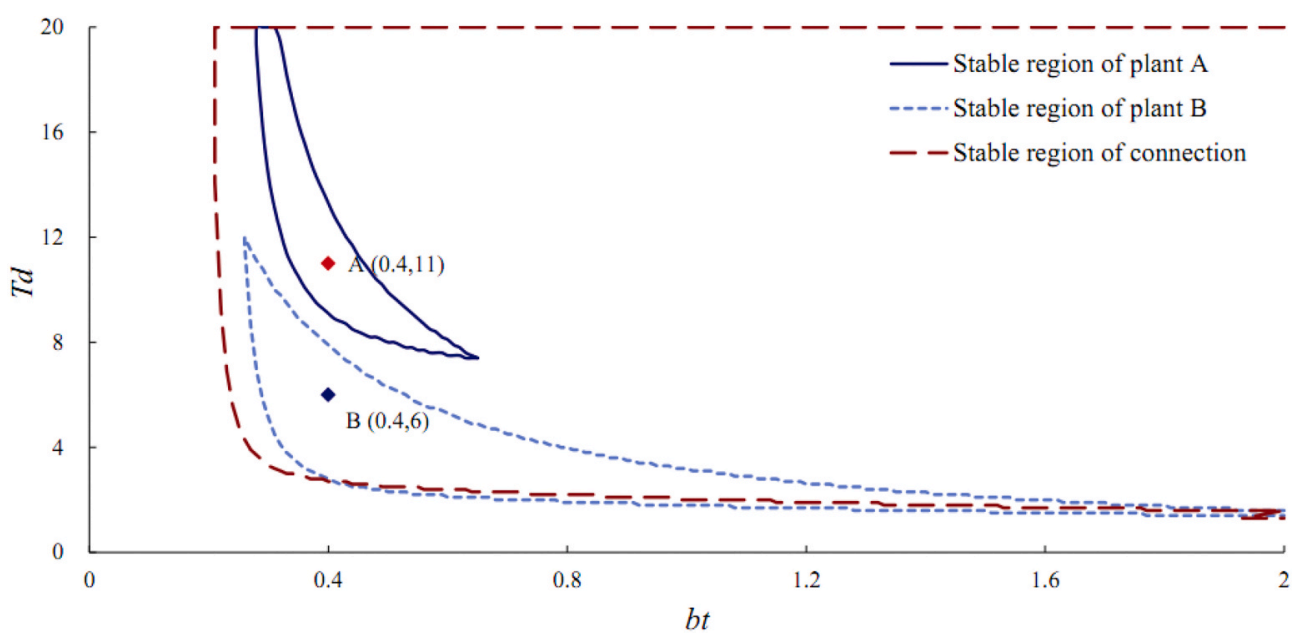

Fig. 13. Stable region under different plants [20]. 


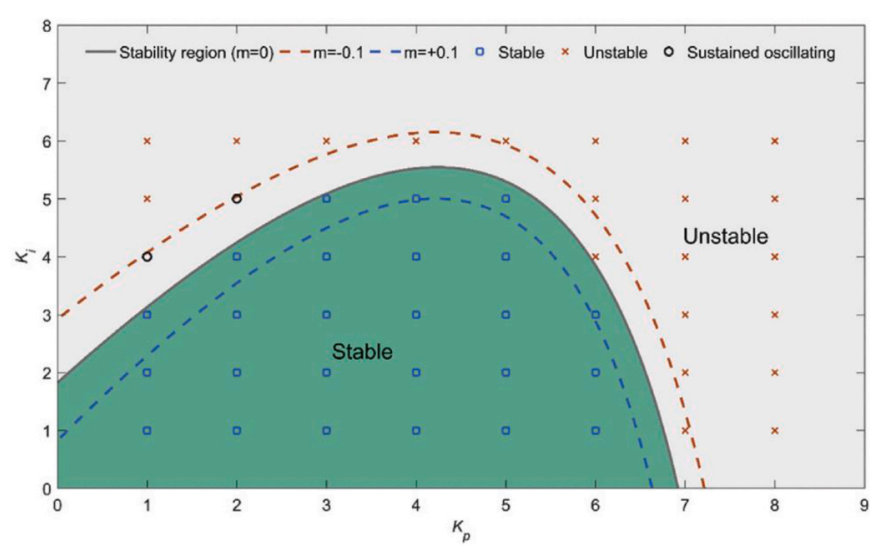

Fig. 14. The stability and stability margin regions [41].

power grid operational condition, while this method needs 5 min to allow the transient control strategy to cope with accidents. Regarding online real-time control, the control measures and control quantities of the relevant control equipment in the power grid are calculated online when a fault occurs. Then, the real-time controller can be implemented promptly, accurately, and reliably using high-speed communication. This process requires a high calculation speed of stability control, generally within $0.2 \mathrm{~s}$. Because the control algorithm's technology is limited, the calculation speed cannot scale up to the requirement of an online real control, so the existing control strategy mostly depends on the offline control strategy $[114,115]$. Here, different control methods based on the offline control strategy are reviewed, including the classical and modern control methods. Classical control theory has been extensively used in the conventional method of turbine governor design, such as PID control. Similarly, recent investigations have stressed the significance of the modern control theory. The application of modern control techniques in a hydropower plant is an area of considerable interest. Table 13 briefly reviews different control methods.
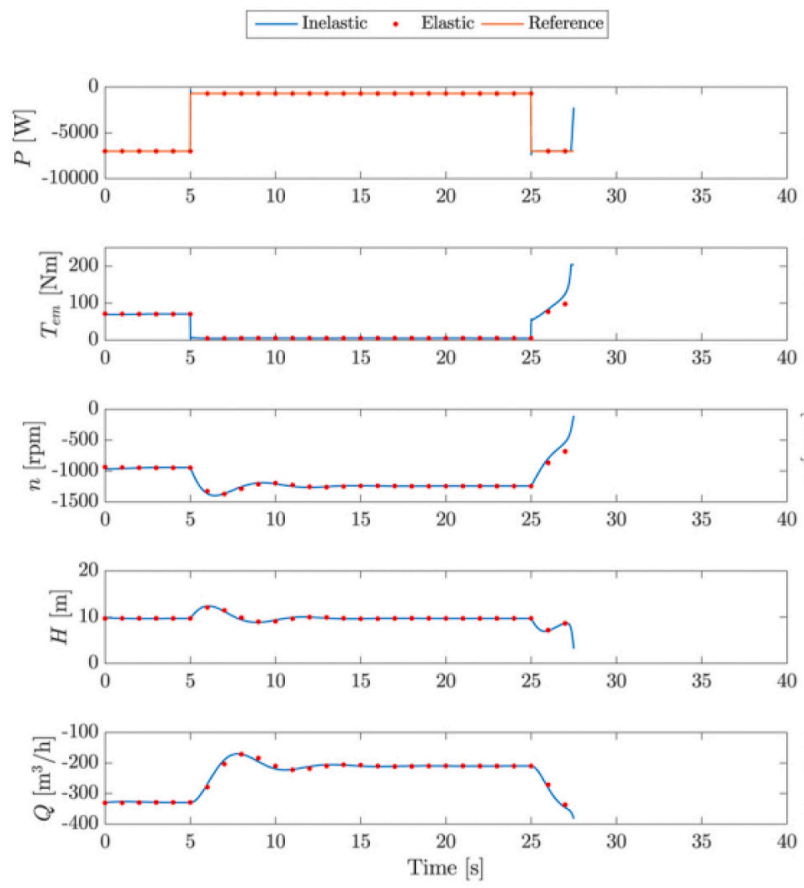

(a)

Fig. 15. Simulation results with two different control methods [112]. (a) Direct control method using electromagnetic torque; (b) Indirect control method using rotational speed. $P, T_{e m}, n, H$, and $Q$ are the power, electromagnetic moment, rotational speed, head, and flow, respectively.

\subsection{The classic control method}

The classical PID control is a preferred selection because of its robustness and practicability. It accounts for $84 \%$ in studing the control [42]. Although it is widely used in various fields, this control method has some drawbacks, such as limitations in dealing with complex systems and time-delay systems.

\subsection{Modern/artificial intelligence (AI) control method}

To overcome the drawbacks of traditional control methods, a series of advanced control methods have attracted scholars' attention, such as the fractional-order PID control (FOPID), sliding mode control (SMC), predictive control (PC), fuzzy control (FC), and fault-tolerant control (FTC) $[124,125]$.

\subsubsection{FOPID}

Podlubny extended the classical integer-order PID control to FOPID by introducing the integrator order $\lambda$ and differentiator $\mu$ [35]. The generalized transfer function of FOPID is given by Ref. [126]:

$G(s)=K_{p}+\frac{K_{i}}{s^{\lambda}}+K_{d} s^{\mu}$

Using the discrete transfer function to calculate the FOPID output, it is expressed as [116]:

$u(k)=K_{p} e(k)+\frac{K_{i}}{h_{1}^{-\lambda}} \sum_{j=0}^{k} q_{j} e(k-j)+\frac{K_{d}}{h_{1}^{\mu}} \sum_{j=0}^{k} d_{j} e(k-j)$

Here, $q_{j}$ and $d_{j}$ are written as:

$$
\begin{array}{r}
q_{0}=1 ; \quad q_{j}=\frac{\lambda+j-1}{j} q_{j-1} \\
d_{0}=1 ; \quad d_{j}=1-\frac{\mu+1}{j} d_{j-1}
\end{array}
$$
strategies, and if the improved type is considered, it will exceed $90 \%$
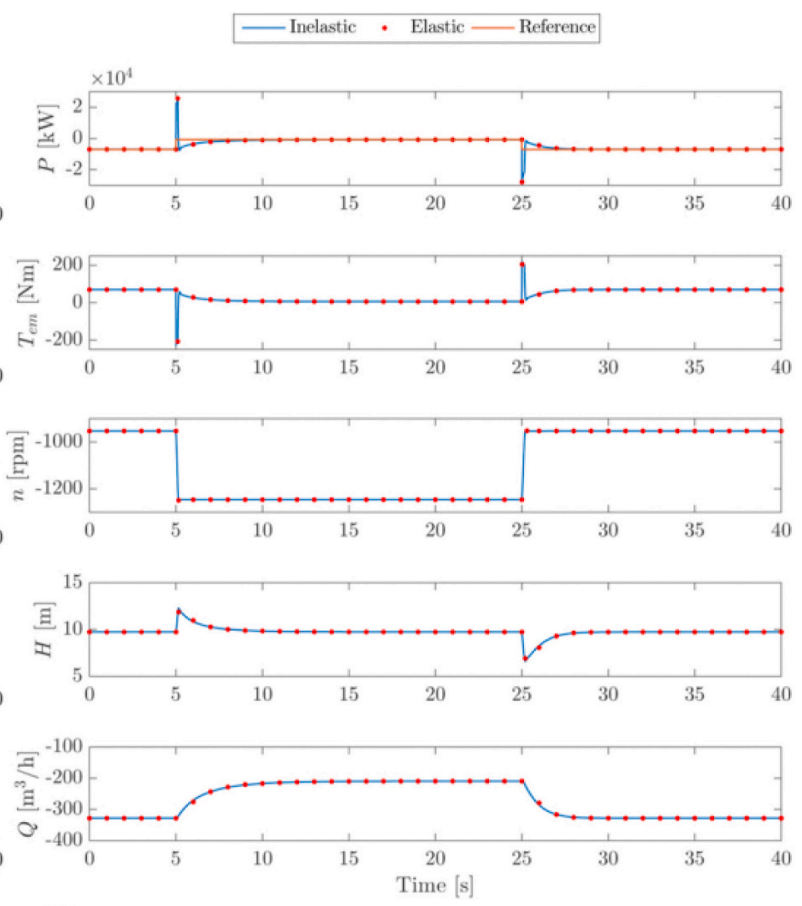

(b) 


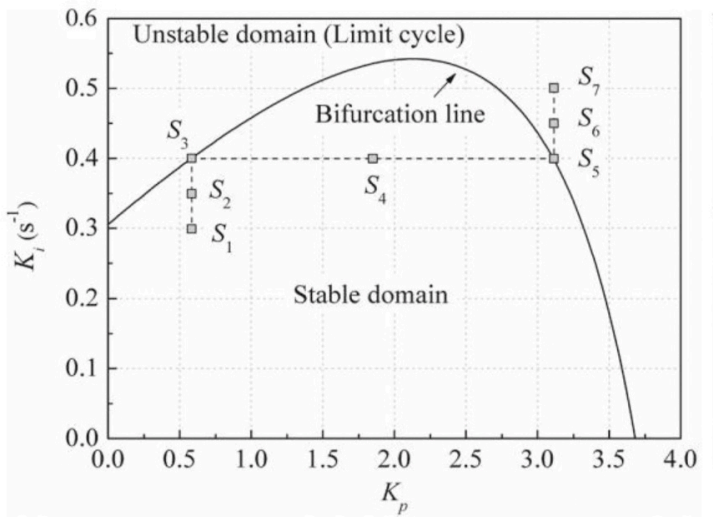

(a)

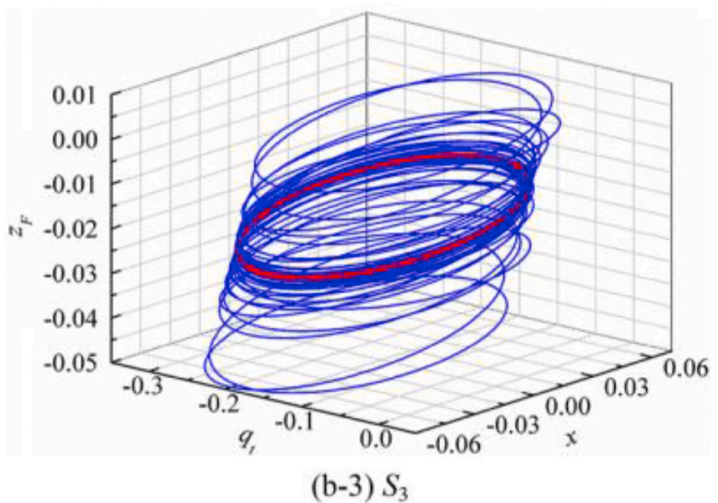

(c)

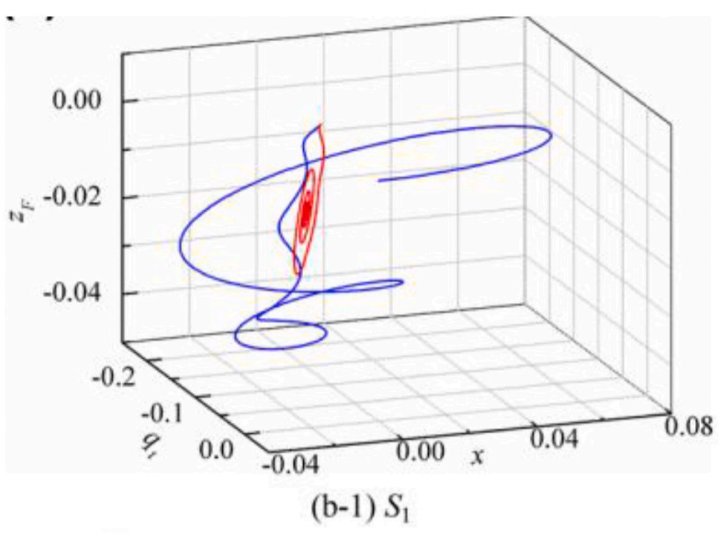

(b)

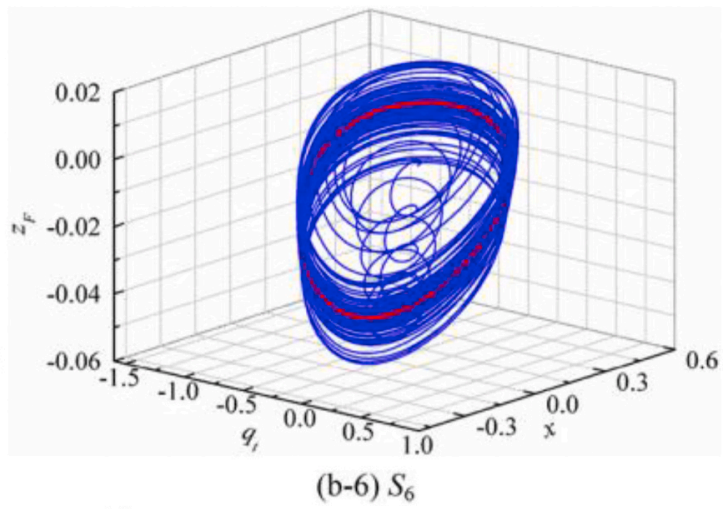

$(d)$

Fig. 16. Dynamic characteristics of the HTGS [60]. (a) stable domain distribution of HTGS; (b) the phase space trajectories of at $S_{1}$; (c) the phase space trajectories at $S_{3} ;(d)$ the phase space trajectories at $S_{6} . q_{t}$ and $Z_{F}$ are the flow of the penstock and the water-level change of the upstream surge tank, respectively.

Table 13

Comparison of control methods.

\begin{tabular}{|c|c|c|c|}
\hline $\begin{array}{l}\text { Control } \\
\text { methods }\end{array}$ & Advantages & Disadvantages & Ref. \\
\hline PID & $\begin{array}{l}\text { Simple structure, } \\
\text { robustness, and easy } \\
\text { implementation }\end{array}$ & $\begin{array}{l}\text { Lower control quality } \\
\text { under complex conditions }\end{array}$ & $\begin{array}{l}{[14,} \\
36, \\
116]\end{array}$ \\
\hline FOPID & $\begin{array}{l}\text { Better adjustability and } \\
\text { flexibility and greater } \\
\text { freedom in design }\end{array}$ & $\begin{array}{l}\text { Complex parameter } \\
\text { optimization problems }\end{array}$ & $\begin{array}{l}{[116,} \\
117]\end{array}$ \\
\hline SMC & $\begin{array}{l}\text { Robustness against } \\
\text { disturbances, insensitivity to } \\
\text { model errors, more freedom } \\
\text { in design }\end{array}$ & $\begin{array}{l}\text { Chattering phenomena due } \\
\text { to discontinuity of the sign } \\
\text { function }\end{array}$ & $\begin{array}{l}{[54,} \\
118, \\
119]\end{array}$ \\
\hline FC & $\begin{array}{l}\text { Strong anti-interference } \\
\text { ability, fast response, simple } \\
\text { design, and easy } \\
\text { implementation }\end{array}$ & $\begin{array}{l}\text { Diffcult to construct fuzzy } \\
\text { rules and membership } \\
\text { functions }\end{array}$ & $\begin{array}{l}{[15,} \\
54, \\
120]\end{array}$ \\
\hline FTC & $\begin{array}{l}\text { Manage component failures } \\
\text { and maintain good control } \\
\text { qualities }\end{array}$ & $\begin{array}{l}\text { Greatly influenced by the } \\
\text { delay of fault detection and } \\
\text { separation, resulting in a } \\
\text { serious stability problem }\end{array}$ & $\begin{array}{l}{[121,} \\
122]\end{array}$ \\
\hline PC & Easy implementation & $\begin{array}{l}\text { Excessive computation but } \\
\text { difficulty in achieving fast } \\
\text { control and long prediction }\end{array}$ & [123] \\
\hline
\end{tabular}

where $h_{1}$ and $e$ are the sampling period and control error, respectively.

The FOPID is a topical issue in research given its better adjustability and flexibility. It has been widely applied in different fields, such as nuclear energy, wind energy, and hydro energy [127]. Moreover, related literature has shown that the FOPID method has advantages over the traditional PID method [116]. Apart from the advantages, one of the main challenges is parameter optimization.

\subsubsection{Sliding mode control (SMC)}

SMC has the advantage of high robustness against disturbances and insensitivity to model errors. This provides designers with more freedom and satisfies special requirements and certain robustness conditions $[118,119]$. When the load changes, the speed control is conducted to keep the power quality. The speed deviation signal (i.e., the difference between the generator speed, $x(\mathrm{t})$, and the referenced speed) is transformed into the regulation signal, $u(\mathrm{t})$, based on SMC rule. Then, the guide-vane opening is changed according to $u(t)$ to adjust the hydro-turbine flow. Finally, the regulated variable $x(\mathrm{t})$ is controlled to align with the referenced speed. The SMC law is the switching control $\left(u_{e q}\right)$ coupled with the equivalent control $\left(u_{s w}\right)$, namely, $u=u_{s w}+u_{e q}$ (see Fig. 17) [54]. Moreover, sgn(s) presents the sign function, and $\operatorname{sgn}(s)=1$ when $s>0, \operatorname{sgn}(s)=0$ when $s=0$, and $\operatorname{sgn}(s)=-1$ when $s<0$. Nevertheless, the SMC easily leads to the 'chattering' problem owing to the discontinuity in the sign function, resulting in low control accuracy.

\subsubsection{Fuzzy control (FC)}

FC has the advantages of a simple design and anti-interference ability. It is suitable for uncertain signals/systems. Some hydropower plants have successfully applied FC by replacing the PID controller [15, $54,120]$. It is also suitable to deal with systems with complexity or high nonlinearity [15]. However, it is difficult to construct fuzzy rules and membership functions, which are often determined by operational experiences and intuitiveness [119]. As shown in Fig. 18, the core control task of FC is to regulate the generator speed $x(\mathrm{t})$ tracking the reference speed $r(\mathrm{t})$ by regulating the guide-vane opening, where the guide-vane opening is controlled using the output signal $u(t)$. Specifically, the 


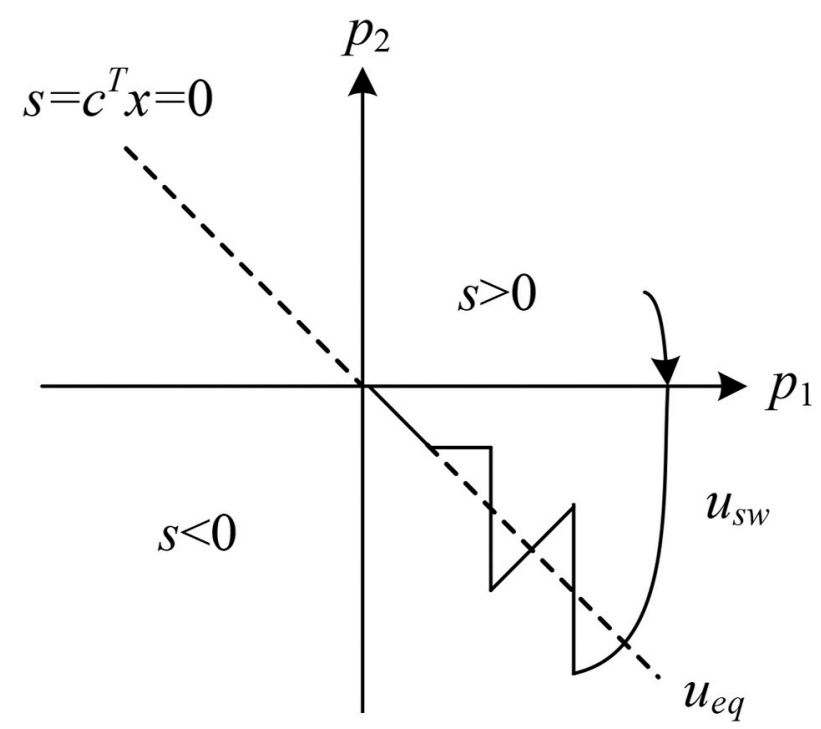

Fig. 17. The sliding mode controller [54]. $p_{1}$ and $p_{2}$ denote the sliding mode surface.

signal deviation, $e_{k}$, at the time, $k$, is the deviation between the measured and desired speed, i.e., $e_{k}=x_{k}-r_{k}$. To minimize the signal deviation, the input signal, $e_{k}$, is converted to the regulation signal, $u_{k}$, through the FC system. Then, $u_{k}$ is used as the input signal of the hydroelectric system to regulate the guide-vane opening to control the generator speed.

\subsubsection{Fault-tolerant control}

Fault-tolerant control (FTC) can manage any malfunctions and maintain system properties simultaneously [121]. It automatically deals with faults based on: the active or passive fault-tolerant control scheme (AFTCS/PFTCS) $[12,16,128]$. The PFTCS is robust enough for a certain set of presumed faults, while AFTCS reacts actively to system faults using a control accommodation method. Thus, the stability and the final performance of the system are maintained [121]. Fig. 19 demonstrates how AFTCS and PFTCS are achieved. As for AFTCS in Fig. 19(a), the fault signal $(\widehat{f})$ generated from the Fault Detection and Diagnosis (FDD) module is input into the FTC module to compensate for the actuator fault effect. Then, the control signal $(\widehat{u})$ is generated through Digital-to-Analog (D/A) converters. The servo mechanism drives the guide-vane opening $(y)$ by the control signal $(\widehat{u})$ to carry out the demand motion, i.e., adjusting the generator speed $x(\mathrm{t})$ to minimize the deviation between the output speed and reference speed. Regarding PFTCS in Fig. 19(b), the process of coping with faults in PFTCS is similar to that of AFTCS. It is worth highlighting that the difference between these two methods is the fault-signal-generating process. PFTCS conducts the online system identification first, and then the fault tolerance signal is generated through the parameter adaption mechanism. Finally, the adaptive controller utilizes the output signal $(y)$ from the servo mechanism to control $x(\mathrm{t})$ from the hydraulic system.

In general, FTC can manage any component failures and to maintain good control qualities. Nevertheless, there are some drawbacks. FTC is influenced by the delay in fault detection and separation, and that delay can cause a serious stability problem [122].

\subsubsection{Predictive control}

In 1967, Lee and Markus first proposed the concept of predictive control (PC) [129]. Chen and Shaw first developed nonlinear PC using the Lyapunov function [130]. It predicts a system's future state using a discrete model [123]. Moreover, it is easy to apply and couples with traditional methods; for example, it can be combined with neural networks or the adaptive algorithm. The flowchart of the adaptive PC algorithm and the implementation of the PC method in a hydropower plant are shown in Fig. 20(a) [131] and 20(b) [15], respectively. To successfully implement the PC method, the first step is to collect the mechanical power sequence, $p_{(k)}$, which is used as the input signal in step 2 . In step 2 , the predicted mechanical power $p^{{ }^{\prime}(k)}$ is generated by an adaptive neuroidentifier (ANI). Then, according to the difference

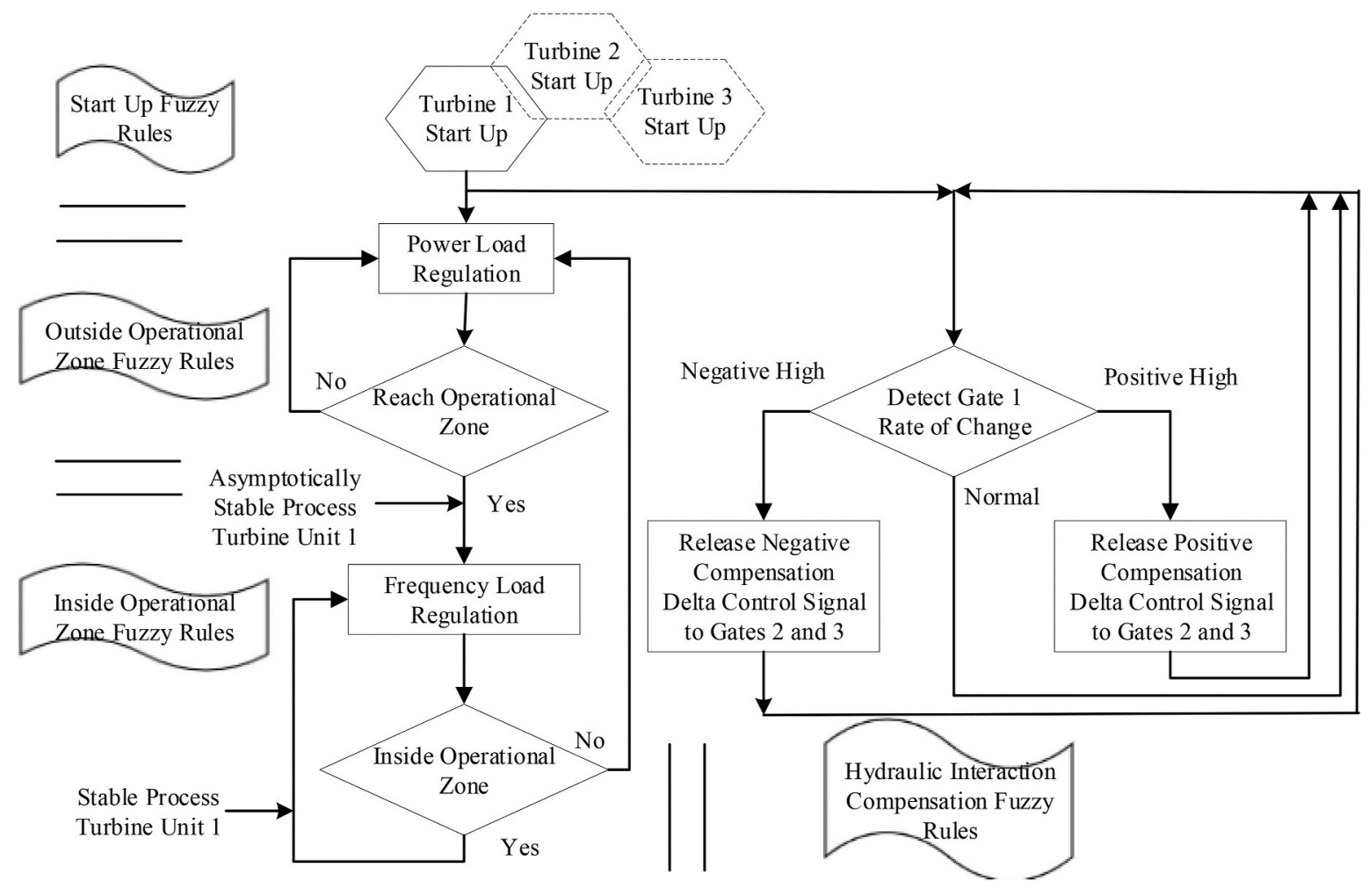

Fig. 18. FC flowchart of a plant with three turbines [120]. 


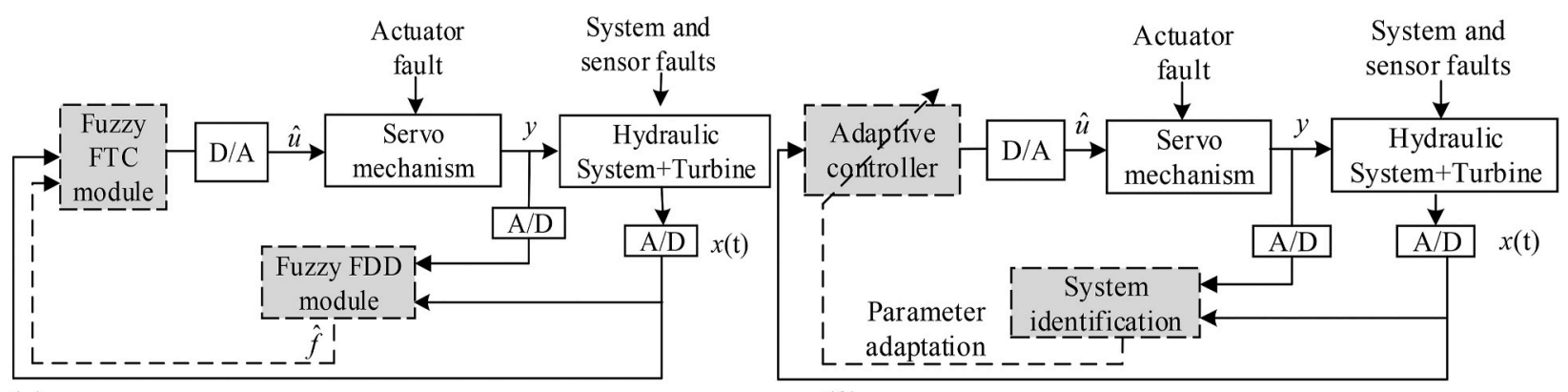

(a)

(b)

Fig. 19. Fault tolerant control schemes: (a) Diagram of AFTCS; (b) Diagram of PFTCS [16].

between $p_{(k)}$ and $p_{\hat{(k)}}$, the weights are updated based on the cost function $J_{i}(k)$ in step 3 . The next step is to generate the controller's output $u(k)$ by an adaptive neurocontroller (ANC). Based on the updated weights in step 3 , the predicted power $p^{\wedge}(k+1)$ is produced by ANI under the regulation of $u(k)$. By computing the deviation between $p^{\wedge}{ }_{(k+1)}$ and the reference signal, the weights of ANC are updated utilizing the back-propagation method in step 6 . This process is repeated during each sampling period to achieve the target that the controlled process output can track the reference value [15]. The most advantageous aspect of PC is that it can predict the future states and take corresponding control measures to keep the system in a high-quality state. Apart from the merits, the main drawbacks of this method are excessive computation and difficulty achieving fast control and long prediction [123].

\subsection{Hybrid control method}

Although the single control method has its advantages, each method has its limitations. To overcome them, the hybrid control is a better choice to combine the advantages of each method to achieve a better control performance [54]. For example, Chen et al. [36] proposed a Fuzzy Sliding Mode Control (FSMC) based on FC and SMC (see Fig. 21 (a)) to overcome the chattering effects of SMC. The speed signal of the HTGS was selected as the input signal of the fuzzy system, and then it was handled using the fuzzy rule. The processed signal was converted to a control signal using SMC rule to drive the servo system to adjust the guide-vane opening to control system speed. The simulation results based on PID, SMC, and FSMC are shown in Fig. 21(b). The results clearly showed that FSMC had a better performance in reducing chatting and overshoot in both the unload condition and the uncertain load condition.

To overcome the control problem of the HTGS with elastic water hammer, Li et al. [37] designed a fuzzy-PID controller in Fig. 22(a) and then applied it to a real hydropower plant to evaluate its efficacy in Fig. 22(b). The fuzzy-PID is the combination of the traditional PID and fuzzy logic inference. Based on the input signals, i.e., the speed deviation $(e)$ and differential deviation $\left(e_{c}\right)$, PID parameters were adjusted utilizing fuzzy inference to regulate the controlled plant to achieve system stability. The results showed that the designed controller (red) improved the overshoot more so than the traditional PID controller (blue) and the nonlinear PID controller (green).

Yi et al. [34] designed a T-S SFPC controller coupled with the state feedback predictive control and the Takagi-Sugeno fuzzy model. The controlled objective is the error between the actual output $y(k)$ from the controlled process and prediction output $\widehat{Y}(k)$ from the model inference. The control rule is the combination of the feedback predictive control and the T-S fuzzy model. Then, comparisons of PID, MPC, and T-S SFPC method were carried out. The results showed that the fluctuation of the rotor angel $\delta$ with the SFPC approach was smaller than that of other methods.

Along with the promotion of energy structure reformation towards low-carbon power generation, the structure and operational mode of the power system have become more complex. The demand for a dynamic

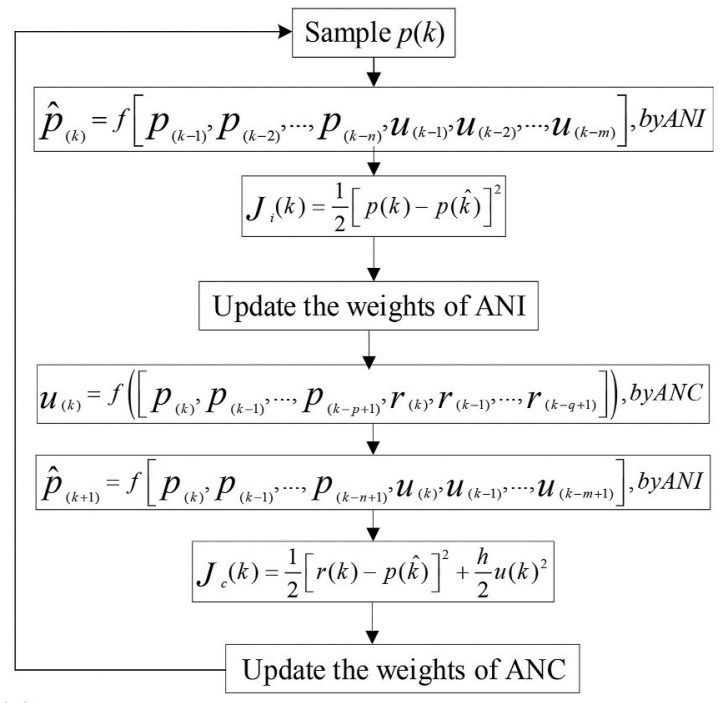

(a)

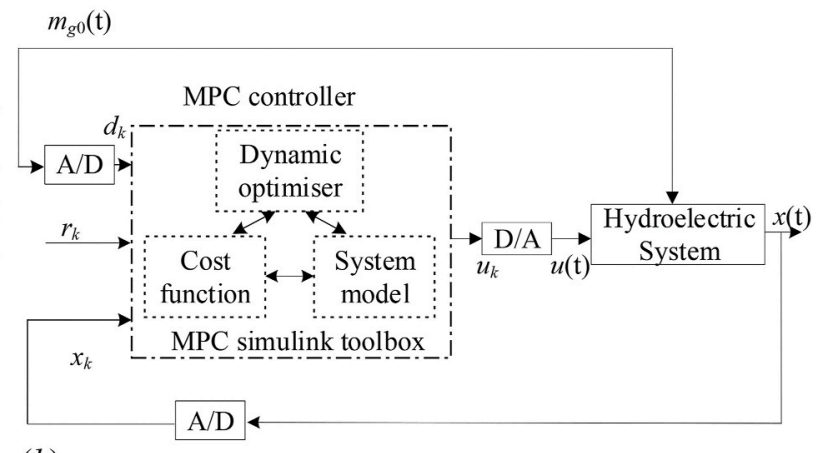

(b)

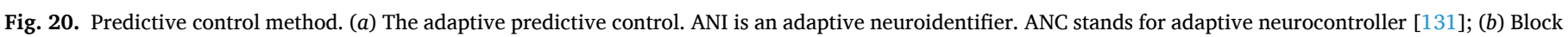

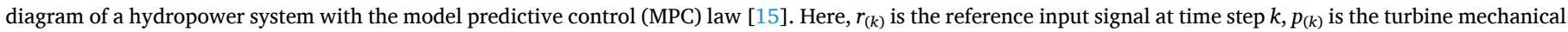

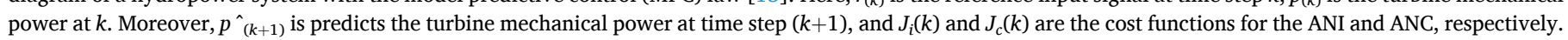




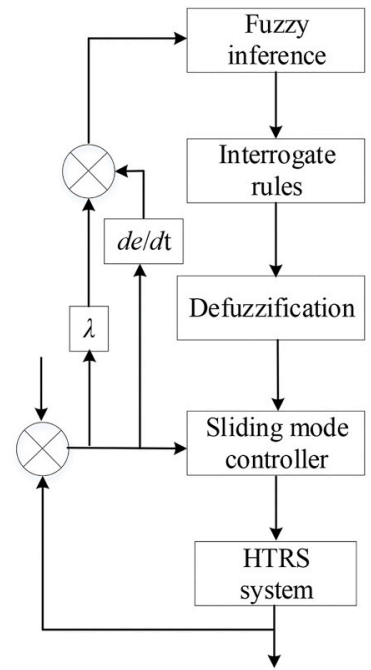

(a)
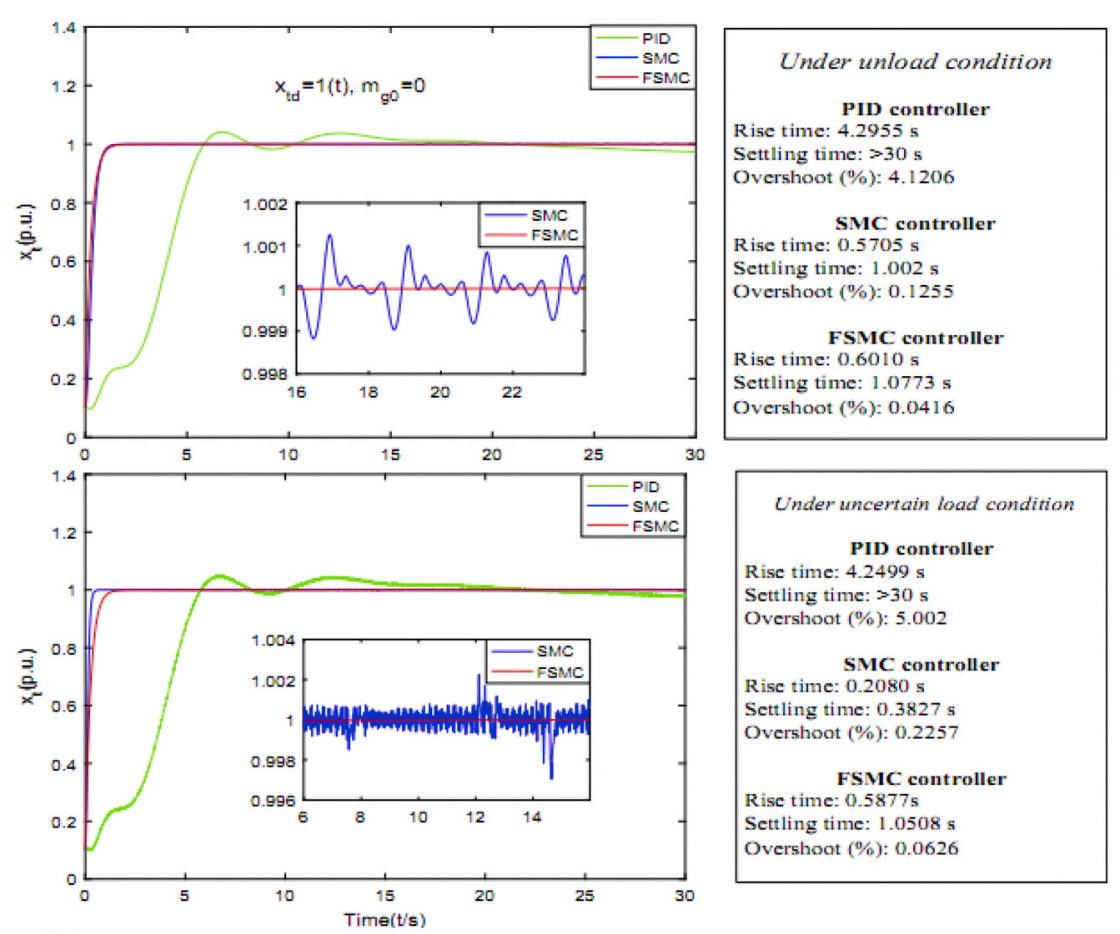

(b)

Fig. 21. FSMC method in a hydropower plant [36]. (a) The diagram of FSMC in the hydro-turbine regulating system (HTRS); (b) Comparisons of different controllers. $x_{t}$ and $x_{t d}$ are the actual and desired speed output. $\lambda$ is a positive constant.

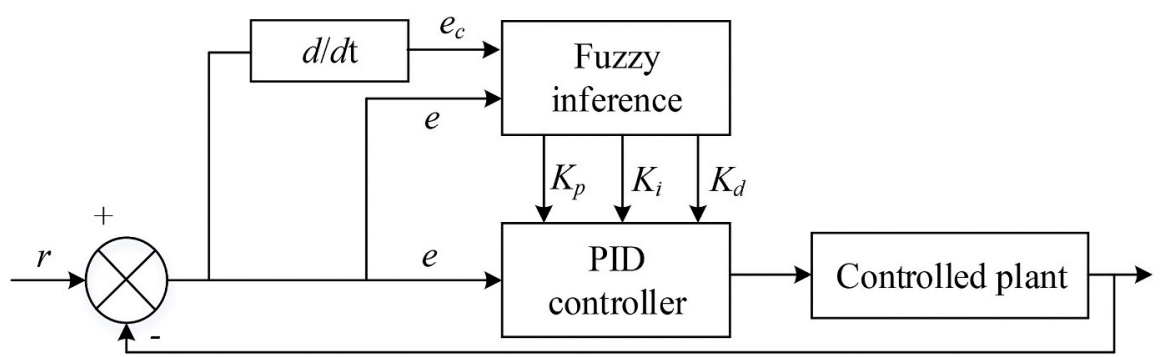

(a)

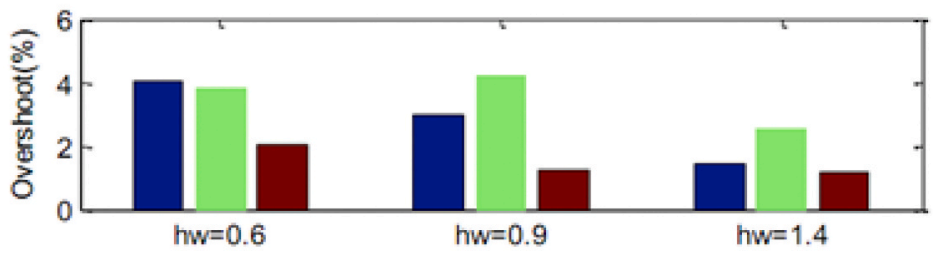

(b)

Fig. 22. The diagram of HTGS with a fuzzy-PID controller [37]. (a) Structure of fuzzy-PID controller; $(b)$ The overshoot of different controllers. $h_{w}$ is the characteristic coefficient of the penstock.

controller response speed is now higher. Fortunately, the online quasireal-time control has attracted more attention. Not limited to online quasi-real-time control, establishing an online real-time controller is the final goal of the continuous improvement, enrichment, updating, and development of power system theory and technical means.

\section{Challenges}

Under the current energy structure of China, thermal power, gas power, nuclear power, and hydropower can undertake peak and frequency regulation. In the scenario of a power system without hydropower: 1) For traditional thermal units, the minimum operational load is high owing to the limitation of technical means and heating requirements, leading to a lack of flexibility in peak and frequency regulation that makes it difficult to meet the power grid requirements. 2) Regarding nuclear power units, the power regulation rate is about $0.25 \%-5 \%$ of the rated capacity per minute [132]. Its peak and frequent operation have a certain impact on the safety and economy of the units' operation. 3) For gas-fired units, although they have the advantages of fast start-up and stoppage, flexible operation, and stable and reliable operational performance, their operational cost is high. In addition, the use of thermal and gas power in peak and frequency regulation further leads to an increase in carbon dioxide emissions, which makes it difficult to achieve the strategic goal of sustainable development. Compared with 
thermal power, gas power, and nuclear power, hydropower is clean and pollution-free and has a fast ramp rate, low operational cost, and flexible operation which make it the first choice for the peak and frequency regulation of a power system. However, there is also a stability challenge for the HGUs in dealing with uncertain electric loads from power systems.

\subsection{Combining the HTGS and shaft model}

The shafting vibration is severe in non-optimal conditions, which means that the control effect of the PID governor cannot guarantee the stability of the generator speed. This, in turn, seriously threatens the power generation reliability of the HTGS in non-optimal working conditions. Traditional modeling methods adopt the ideal turbine model based on the linearization characteristics of stable operational points, while this method is dangerously inaccurate for small guide-vane opening conditions. Thus, an accurate model is needed urgently to quantify the interaction mechanism of the HTGS control and shaft vibration. The first challenge is to find appropriate transfer parameters. For example, generator speed is a common parameter for the HTGS and shaft model, but if this parameter only combines the two models, there will be a negligible impact on shaft vibration in the HTGS's control effect. This is because the generator angular frequency is controlled within $0.2 \mathrm{~Hz}$ after passing through the PID controller [5]. The second parameter is the hydraulic force acting on the blade. Forces on the runner blades generate the dynamic torque of the hydro-turbine used in HTGS and the unbalanced hydraulic forces causing the shaft vibration. However, the analytic formula of the hydraulic force is too complex and covers lots of runner parameters, such as the resistance coefficient, $C_{x}$, the excretion coefficient, $s$, and the runner diameter, $D_{r}$ [133]. This is not suitable for large-scale power system simulation. The second challenge is the vortex belt effect in draft tubes [134]. The vortex belt in partial loads has a dramatic influence on the dynamic torque of the hydro-turbine and shaft vibration, which is a complex phenomenon. The dynamic wake vortices, blade passage vortices, tailrace vortices, and clearance vortices of double-row guide-vane cascades are the main causes of runner imbalance and are key factors that cause HTGS instability. The oscillation of hydro-turbine generator units and changes in rotational speed can also lead to sudden changes in sealing clearance force and induce hydraulic imbalances in the runner. Therefore, the coupling mechanism between the adjustment parameters in various conditions and the changes in turbulence state that lead to a hydraulic imbalance in the runner is still unclear. However, the coupling modeling principle is still a work in progress. At present, classical models applying this principle are roughly divided into four categories: the 1D characteristic method + the characteristic curve of hydraulic turbine [135], the equivalent circuit theory + the characteristic curve of hydraulic turbine $+1 \mathrm{D}$ hydro acoustic [136], the transient boundary condition + 3D hydro-turbine [137], and the equivalent circuit theory $+3 \mathrm{D}$ hydro-turbine $+1 \mathrm{D}$ hydro acoustic [138]. However, the transfer parameters and coupling mechanism between the full three-dimensional turbine model and the one-dimensional acoustic model are still immature, and the governor control is not considered in these models. Therefore, developing a general method to combine HTGS and shaft model is an important challenge for reliable generation evaluation of hydraulic turbines in non-optimal conditions. In addition, the control methods are the other challenge because of the high dimensional nonlinearity of the coupling model of the HTGS and shaft.

\subsection{Control methods of HTGS with intermittent renewable energies}

The main challenges of the HTGS to regulate power variation in intermittent renewable energies include: (1) improving the modeling methods of the HTGS to possibly evaluate its potential feasibility, (2) revising the control methods traditionally or seeking new technologies used to eliminate the power-tracking delay and difference, such as variable-speed pumped storage plants. The first challenge is described in subsection 6.1. The second challenge that some researchers have preliminarily studied is summarized in Table 14. Specifically, considering the ongoing complementary projects in China, it has become mandatory to develop more hydropower stations based on an operational strategy of greater flexibility, such as the hybrid wind-hydro power system [139]. Control methods and variable-speed units are currently two effective research directions. The traditional PID controller shows an obvious insufficient regulating capacity problem, as shown in Fig. 23 [30]. This causes the PSGS's power response to lag behind wind power fluctuation, which further impacts the power supply reliability of the hybrid power system. As Fig. 24 shows, the revised control methods not only predict hydropower compensation for intermittent power fluctuation in advance but also consider complementary regulation of power quality [31]. Variable-speed operational is a well-known solution used to enhance the HTGS's flexibility. The advantages of variable-speed units are that they mitigate wind power variations [32], and their trends and challenges are well documented in literature [139]. However, this type of technology is not suitable for traditional hydropower stations like the wind-hydro-solar hybrid complementary system in Yalong River. Thus, the method of revising control methods is one of the least costly but most effective directions for these existing HTGSs.

\subsection{Uncertain nature of load on the overall performance and stability of the hydropower system}

The uncertain nature of the load is mainly from two aspects: 1) uncertain consumption and 2) the uncertain power supply from generation systems. The hydroelectric generating units should be adjusted continuously to suppress power uncertainty in the electric power system. In other words, HGUs should switch from the traditional power supply mode to the regulation mode. For these hydropower stations, the designed output power of HGUs changes from $65 \%$ to $100 \%$. HGUs frequently cross the low- and medium-load areas when they operate in regulation mode. During this process, the pressure pulsation and the HGUs' speed change dramatically, which adds huge security risks to the stable operation of HGUs. To cope with the change in the hydropower operational mode caused by load uncertainty, the current strategy is to optimize the installed capacity of different energies and reserve the capacity of hydropower. Regarding the stable operation of HGUs, the reasonable design of a hydro-turbine runner is an effective method to deal with the variation of HGUs to realize the stable operation of the full load operation of HGUs. This measure has been verified in the Fengman hydropower generating system in China [141]. In addition, the synergism control strategy considering AGC and primary frequency regulation is also an effective method to reduce HGUs' variation during the adjustment and protection calculation of the transient process. This is an area where demand-side management may take positive response measures.

\section{Conclusions}

Not all hydropower plant layouts follow the same pattern because each water source has its own structure. Thus, modular models and stability analysis methods have been proposed to cope with these differences. The unified model of the HTGS was established based on the

Table 14

Summary of preliminary research.

\begin{tabular}{ll}
\hline Challenge & $\begin{array}{l}\text { Preliminarily studied } \\
\text { research }\end{array}$ \\
\hline $\begin{array}{l}\text { Revising control methods to eliminate the power-tracking } \\
\text { delay and difference }\end{array}$ & {$[30,31]$} \\
$\begin{array}{l}\text { Seeking new technologies used to eliminate the power- } \\
\text { tracking delay and difference }\end{array}$ & {$[32,112,140]$} \\
\hline
\end{tabular}




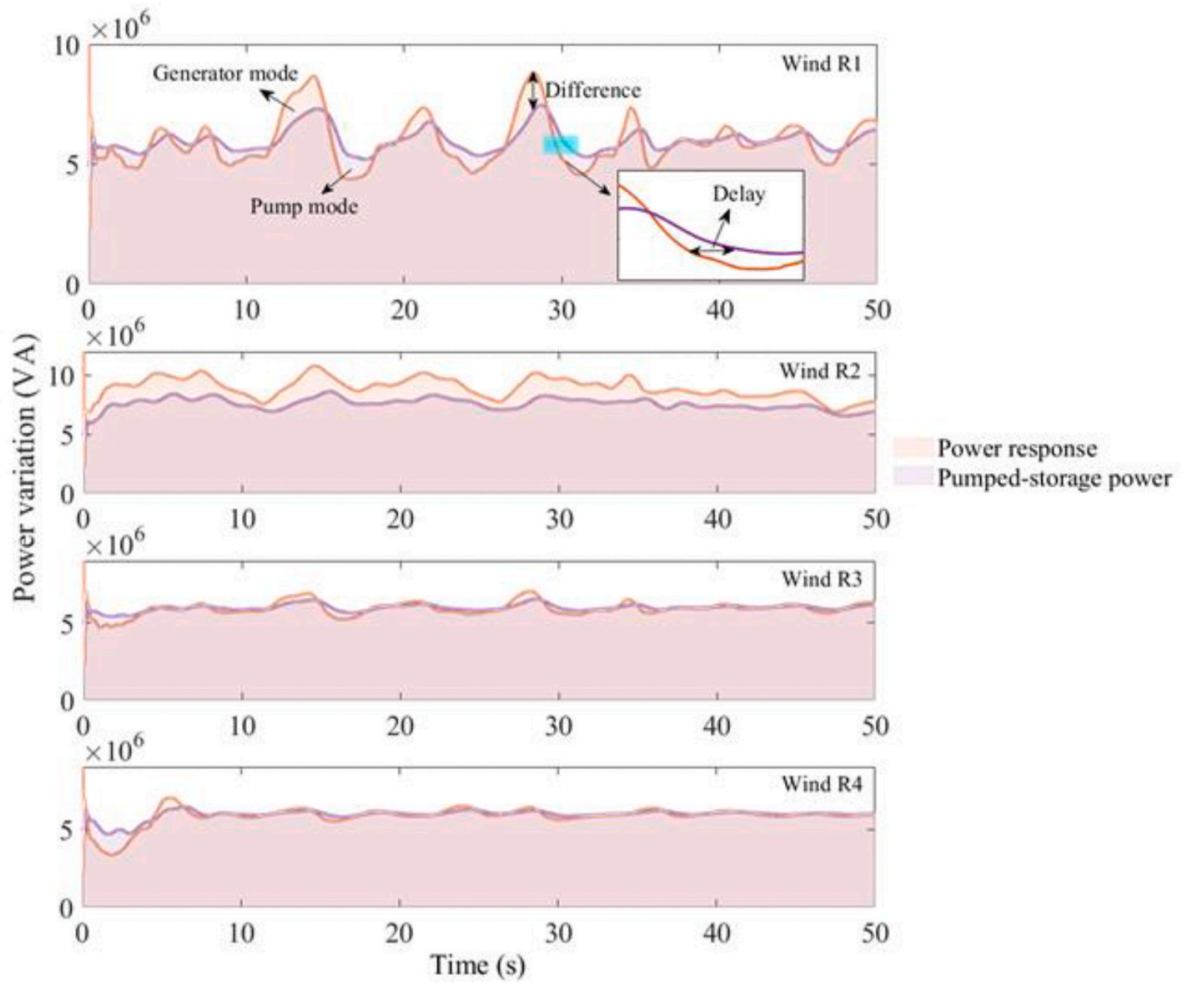

Fig. 23. Power responses of the HTGS under random wind disturbances (R1 to R4) [30]. The power response and pumped-storage power response are shown in solid lines in orange and pink, respectively. The power response represents the pumped-storage demand that needs to be met due to the fluctuation of wind energy, while the pumped-storage power response is the actual response.

(A)

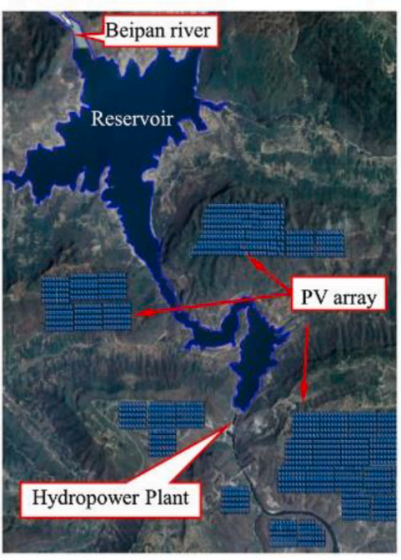

(B)

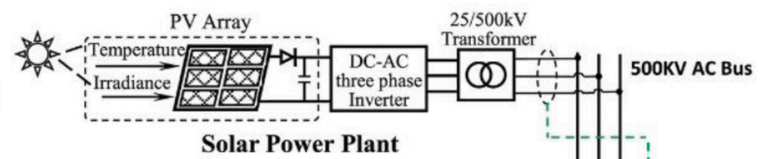

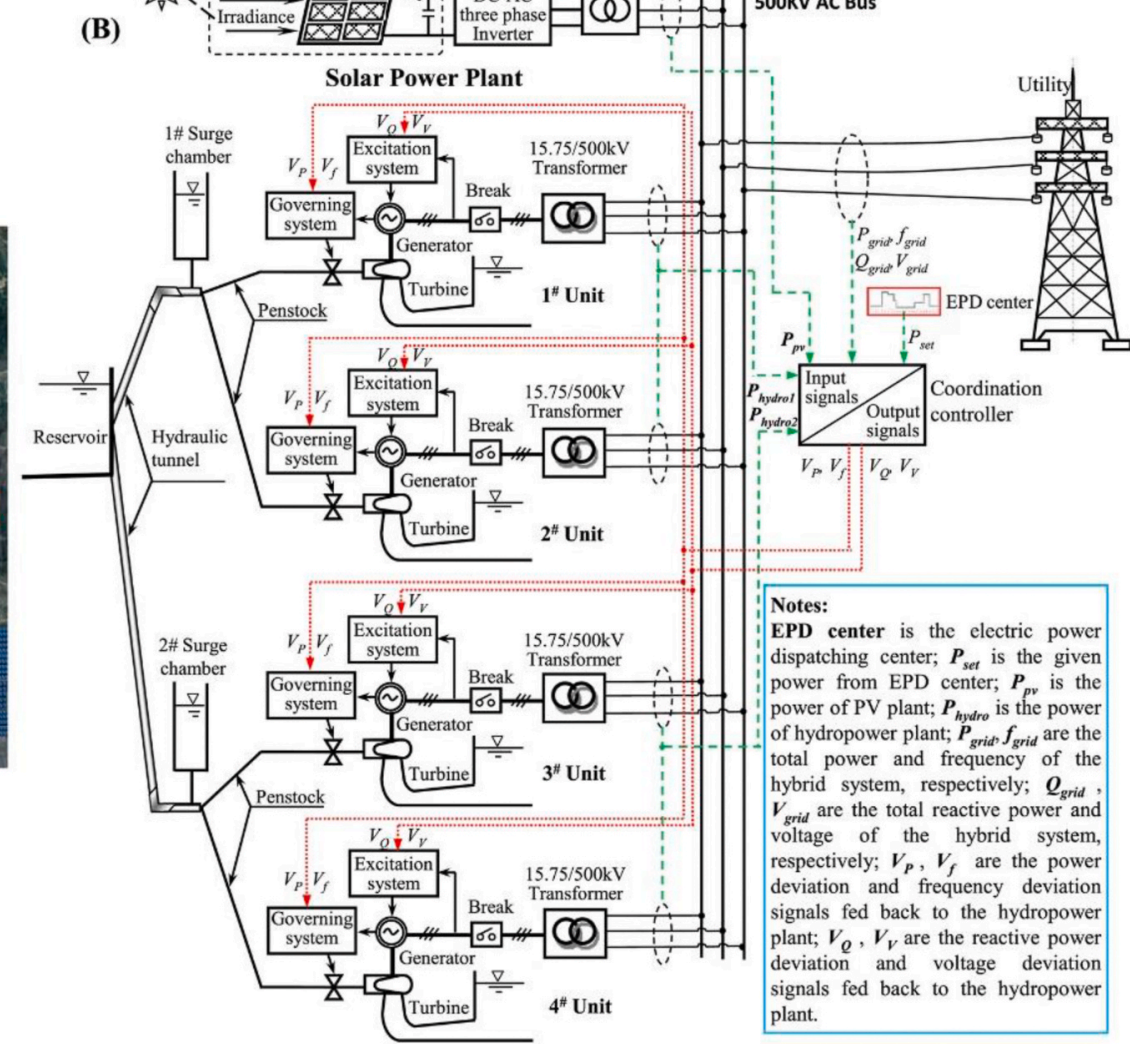

Hydropower Plant

Fig. 24. The scenario of a solar-hydro hybrid system [31]. (A) The map of the hybrid system; (B) The diagram of the hybrid system. 
coupling of modular models. Selecting a suitable unified model and stability analysis method is the key factor to conduct research. The important prerequisite to make a clear choice is an understanding of the characteristics of each model and the stability analysis method, which enable exploring the potential flexibility of the HTGS in mitigating power variations from intermittent renewable energies. The main achievements of this review paper in modeling, stability analysis, and control methods are summarized as follows:

First, applicable conditions of the penstock model, surge tank model, hydro-turbine model, generator model, and governor model were discussed based on the layouts of hydropower plants. The coupling methods using these modular models were classified. Methods of stability analysis, such as the bifurcation theory and Lyapunov theory, were compared from the perspective of advantages, disadvantages, and applications. Additionally, the merits and demerits of the control methods were summarized.

Second, current achievements in the above three areas were described and discussed. Hence, two challenges and possible future development directions were identified:

(1) The first challenge is how to combine the HTGS and shaft model for reliable generation evaluation of the HTGS in non-optimal conditions, and the vortex-belt effect in draft tubes should also be considered during this process. A possible solution to cope with this challenge is to find appropriate transfer parameters to quantify the interaction mechanism of the HTGS and shaft vibration. Additionally, the control methods based on the coupling model of the HTGS and shaft present another obstacle because of the coupling model's high dimensional nonlinearity. Thus, a deep-learning intelligent control algorithm is a possible future research direction.

(2) The second challenge is to revise the control methods traditionally or seek new technologies to eliminate the power-tracking delay and difference when the HTGS is used to regulate the power variation of intermittent renewable energies. The possible revised control methods can not only predict hydropower compensation for intermittent power fluctuation in advance but also consider complementary regulation of power quality. Variable-speed technology is another possible solution to enhance the HTGS's flexibility.

(3) The third challenge is how to cope with the uncertain nature of the load. The possible method to deal with this challenge is to optimize the installed capacity of different energies, to reserve the capacity of hydropower, and to make a synergism control strategy that considers the AGC and primary frequency regulation during the adjustment and protection calculation of a transient process.

\section{Declaration of competing interest}

The authors declare that they have no known competing financial interests or personal relationships that could have appeared to influence the work reported in this paper.

\section{Acknowledgments}

This work was supported by the Scientific Research Foundation of the Fundamental Research Funds for the Northwest A\&F University (Z1090220172), the Natural Science Foundation of Shaanxi Province of China (2019JLP-24), and the Water Conservancy Science and Technology Program of Shaanxi Province (2018slkj-9).

\section{References}

[1] Sawle Y, Gupta SC, Bohre AK. Review of hybrid renewable energy systems with comparative analysis of off-grid hybrid system. Renew Sustain Energy Rev 2018; 81:2217-35.

[2] International hydropower association (IHA). Hydropower status report sector trends and insights. 2019.

[3] Deshmukha MK, Deshmukh SS. Modeling of hybrid renewable energy systems. Renew Sustain Energy Rev 2008;12:235-49.

[4] Caralis G, Papantonis D, Zervos A. The role of pumped storage systems towards the large scale wind integration in the Greek power supply system. Renew Sustain Energy Rev 2012;16:2558-65.

[5] Xu BB, Chen DY, Venkateshkumar M, Xiao Y, Yue Y, Xing YQ, Li PQ. Modeling a pumped storage hydropower integrated to a hybrid power system with solar-wind power and its stability analysis. Appl Energy 2019;248:446-62.

[6] Shi YS, Zhou JZ, Lai XJ, Xu YH, Guo WC, Liu BN. Stability and sensitivity analysis of the bending-torsional coupled vibration with the arcuate whirl of hydroturbine generator unit. Mech Syst Signal Process 2021;149:107306.

[7] Li HH, Chen DY, Zhang H, Wu CZ, Wang XY. Hamiltonian analysis of a hydroenergy generation system in the transient of sudden load increasing. Appl Energy 2017; 185:244-53.

[8] Liu GM, Liu DH. Hydro-turbine governing system. Nan Chang: Jiangxi university Press; 2006 [in Chinese)].

[9] Xu BB. Fractional-order dynamic model of a hydropower generation system and its stability. Yangling: Northwest A\&F University; 2017 [in Chinese)].

[10] Yang WJ, Norrlund P, Bladh J, Yang JD, Lundin U. Hydraulic damping mechanism of low frequency oscillations in power systems: quantitative analysis using a nonlinear model of hydropower plants. Appl Energy 2018;212:1138-52.

[11] Xu BB, Chen DY, Zhang H, Wang FF. Modeling and stability analysis of a fractional-order Francis hydro-turbine governing system. Chaos, Solit Fractals 2015;75:50-61.

[12] Yi YP, Chen DY. Disturbance observer-based backstepping sliding mode faulttolerant control for the hydro-turbine governing system with dead-zone input. ISA Trans 2019;88:127-41.

[13] Ling DJ, Tao Y. An Analysis of the Hopf bifurcation in a hydroturbine governing system with saturation. IEEE Trans Energy Convers 2006;21(2):512-5.

[14] Kishor N, Saini RP, Singh SP. A review on hydropower plant models and control. Renew Sustain Energy Rev 2007;11:776-96.

[15] Finotti S, Simani S, Alvisi S, Venturini M. Benchmarking of advanced control strategies for a simulated hydroelectric system. 13th European Workshop on Advanced Control and Diagnosis (ACD 2016). IOP Conf. Series: J Phys Conf 2017; 783:012041.

[16] Simani S, Alvisi S, Venturini M. Fault tolerant control of a simulated hydroelectric system. Contr Eng Pract 2016;51:13-25.

[17] Andersson G, Donalek P, Farmer R, Hatziargyriou N, Kamwa I, Kundur P, Vittal V. Causes of the 2003 major grid blackouts in north America and Europe, and recommended means to improve system dynamic performance. IEEE Trans Power Syst 2005;20(4):1922-8.

[18] Berizzi A. The Italian 2003 blackout. In: Proceedings of the IEEE PES general meeting. Denver CO; 2004.

[19] Riasi A, Tazraei P. Numerical analysis of the hydraulic transient response in the presence of surge tanks and relief valves. Renew Energy 2017;107:138-46.

[20] Yu XD, Yang XW, Zhang J. Stability analysis of hydro-turbine governing system including surge tanks under interconnected operation during small load disturbance. Renew Energy 2019;133:1426-35.

[21] Guo WC, Yang JD, Yang WJ, Chen JP, Teng Y. Regulation quality for frequency response of turbine regulating system of isolated hydroelectric power plant with surge tank. Int J Elec Power 2015;73:528-38.

[22] Ji K, Liu WL. A discussion of the condition for setting tailwater surge tank. J Zhongyuan Inst Technol 1991;(4):17-21 [in Chinese)].

[23] Guo WC, Yang JD. Modeling and dynamic response control for primary frequency regulation of hydro-turbine governing system with surge tank. Renew Energy 2018;121:173-87.

[24] Ni YX, Chen SS, Zhang BL. Theory and analysis of dynamic power system. Beijing: Tsinghua university press; 2002 [in Chinese)].

[25] Sharafutdinov K, Gorjao LR, Matthiae M, Faulwasser T, Witthaut D. Rotor-angle versus voltage instability in the third-order model for synchronous generators. Chaos 2018;28(3):033117.

[26] Xu BB, Chen DY, Tolo S, Patelli E, Jiang YL. Model validation and stochastic stability of a hydro-turbine governing system under hydraulic excitations. Int $\mathrm{J}$ Elec Power 2018;95:156-65.

[27] Yang WJ, Yang JD, Guo WC, Norrlund P. Response time for primary frequency control of hydroelectric generating unit. Int J Elec Power 2016;74:16-24.

[28] Xu BB, Chen DY, Zhang H, Wang FF, Zhang XG, Wu YH. Hamiltonian model and dynamic analyses for a hydro-turbine governing system with fractional item and time-lag. Commun Nonlinear Sci Numer Simulat 2017;47:35-47.

[29] Pérez-Díaz JI, Sarasúa JI, Wilhelmi JR. Contribution of a hydraulic short-circuit pumped-storage power plant to the load-frequency regulation of an isolated power system. I Int J Elec Power 2014;62:199-211.

[30] Xu BB, Li HH, Campana PE, Hredzak B, Chen DY. Dynamic regulation reliability of a pumped-storage power generating system: effects of wind power injection. Energy Convers Manag 2020. https://doi.org/10.1016/j. enconman.2020.113226.

[31] Zhang ML, Xie TT, Zhang CB, Chen D, Mao C, Shen CH. Dynamic model and impact on power quality of large hydro-photovoltaic power complementary plant. Int J Energ Research 2019;43(9):4436-48. 
[32] Yang WJ, Yang JD. Advantage of variable-speed pumped storage plants for mitigating wind power variations: integrated modelling and performance assessment. Appl Energy 2019;237:720-32.

[33] Xu BB, Chen DY, Zhang XL, Alireza R. Parametric uncertainty in affecting transient characteristics of multi-parallel hydropower systems in the successive load rejection. Int J Elec Power 2019;106:444-54.

[34] Yi YP, Zhang ZW, Chen DY, Zhou R, Patelli E, Tolo S. State feedback predictive control for nonlinear hydro-turbine governing system. J Vib Contr 2018;24(21): 4945-59.

[35] Podlubny I. Fractional-order systems and PI-lambda-D-mu-controllers. IEEE Trans Automat Contr 1999;44(1):208-14.

[36] Chen ZH, Yuan XH, Yuan YB, Lei XH, Zhang BO. Parameter estimation of fuzzy sliding mode controller for hydraulic turbine regulating system based on HICA algorithm. Renew Energy 2019;133:551-65.

[37] Li CS, Mao YF, Zhou JZ, Zhang N, An XL. Design of a fuzzy-PID controller for a nonlinear hydraulic turbine governing system by using a novel gravitational search algorithm based on Cauchy mutation and mass weighting. Appl Soft Comput 2017;52:290-305.

[38] Zhang JJ, Chen DY, Zhang H, Xu BB, Li HH, Aggidis GA. Fast-slow dynamic behaviors of a hydraulic generating system with multi-timescales. J Vib Contr 2019;25(23-24):2863-74.

[39] Cheng YC. Automatic regulation of hydro-turbine. Beijing: China Water \& Power Press; 2010 [in Chinese)].

[40] Liu D, Wang X, Peng YS, Zhang H, Xiao ZH, Han XD, Malik OP. Stability analysis of hydropower units under full operating conditions considering turbine nonlinearity. Renew Energy 2020;154:723-42.

[41] Yang WJ, Yang JD, Zeng W, Tang RB, Hou LY, Ma AT, Zhao ZG, Peng YM. Experimental investigation of theoretical stability regions for ultra-low frequency oscillations of hydropower generating systems. Energy 2019;186:115816.

[42] Fang HQ. Nonlinear control strategy for hydraulic turbine generating unit and its industrial application research. Nanjing: Hohai university; 2005 [in Chinese)].

[43] Wang C, Zhang DH, Tang ZX. Hopf bifurcation analysis of nonlinear hydroturbine governing system. Water Resour Power 2018;36(9):148-51 [in Chinese)].

[44] Kishor N, Singh SP, Raghuvanshi AS. Dynamic simulations of hydro turbine and its state estimation based LQ control. Energy Convers Manag 2006;47:3119-37.

[45] Ye LQ, Wei SP, Li ZH, Malik OP, Hope GS. Field tests and operation of a duplicate multiprocessor-based governor for water turbine and its further development. IEEE Trans Energy Convers 1990;5:225-31.

[46] Zeng Y, Zhang LX, Qian J, Xu TM, Guo YK. Differential algebra model simulation for hydro-turbine with elastic water column. Journal of Drainage and Irrigation Machinery Engineering 2014;32(8):691-7 [in Chinese)].

[47] Sarasúa JI, Elías P, Martínez-Lucas G, Pérez-Díaz JI, Wilhelmi JR, Já Sánchez. Stability analysis of a run-of-river diversion hydropower plant with surge tank and spillway in the head pond2014. The Scientific World Jo; 2014. p. 874060.

[48] Kamath GK, Jagannathan K, Raina G. Stability, convergence and Hopf bifurcation analyses of the classical car-following model. Nonlinear Dynam 2019;96: 185-204.

[49] Wei JQ, Xiao MQ. Lyapunov Function-based stochastic stability of power system. J North China Electr Power Univ (Soc Sci) 2019;46(1):82-8 [in Chinese)].

[50] Luo HW. Stability and Hopf Bifurcation Study on a class of nonlinear dynamics hydro-turbine governing systems model. Lanzhou: Lanzhou Jiaotong University; 2017 [in Chinese)].

[51] Das D, Roy S, Gupta S. Reconstructing bifurcation behavior of a nonlinear dynamical system by introducing weak noise. Commun Nonlinear Sci Numer Simulat 2019;72:575-85.

[52] Ling DJ. Bifurcation and chaos characteristics of hydro-turbine governing system. Nanjing: Hohai university; 2007 [in Chinese)].

[53] Guo WC, Yang JD. Hopf bifurcation control of hydro-turbine governing system with sloping ceiling tailrace tunnel using nonlinear state feedback. Chaos, Solit Fractals 2017;104:426-34.

[54] Liang J, Yuan XH, Yuan YB, Chen ZH, Li YZ. Nonlinear dynamic analysis and robust controller design for Francis hydraulic turbine regulating system with a straight-tube surge tank. Mech Syst Signal Process 2017;85:927-46.

[55] Chen DY, Ding Cong, Ma XY, Yuan P, Ba DD. Nonlinear dynamical analysis of hydro-turbine governing system with a surge tank. Appl Math Model 2013;37 (14-15):7611-23.

[56] Tarnopolski M. Correlation between the Hurst exponent and the maximal Lyapunov exponent: examining some low-dimensional conservative maps. Physica A 2018;490:834-44.

[57] Rosenstein Michael T, Collins James J, Carlo J, De Luca. A practical method for calculating largest Lyapunov exponents from small data sets. Physica D 1993;65: $117-34$.

[58] Deng YW, Xu BB, Chen DY, Liu J. Stochastic global stability and bifurcation of a hydro-turbine generator. Commun Nonlinear Sci Numer Simulat 2019;72:64-77.

[59] Su WT, Li XB, Lan CF, An S, Wang JS, Li FC. Chaotic dynamic characteristics of pressure fluctuation signals in hydro-turbine. J Mech Sci Technol 2016;30(11): 5009-17.

[60] Guo WC, Yang JD, Chen JP, Wang MJ. Nonlinear modeling and dynamic control of hydro-turbine governing system with upstream surge tank and sloping ceiling tailrace tunnel. Nonlinear Dynam 2016;84(3):1383-97.

[61] Li HH, Chen DY, Gao X, Wang XY, Han QS, Wu CZ. Fast-slow dynamics of a hydropower generation system with multi-time scales. Mech Syst Signal Process 2018;110:458-68.

[62] Zhang H, Chen DY, Wu CZ, Wang XY. Dynamics analysis of the fast-slow hydroturbine governing system with different time-scale coupling. Commun Nonlinea Sci Numer Simulat 2018;54:136-47.
[63] Xu BB, Chen DY, Zhang H, Wang FF. Modeling and stability analysis of a fractional-order Francis hydro-turbine governing system. Chaos, Solit Fractals 2015;75:50-61.

[64] Guo YY. Terminal departures passenger traffic prediction based on chaotic time series. Harbin: Harbin Institute of Technology; 2013 [in Chinese)].

[65] Zhou S, Feng Y, Wu WY, Wang WH. A novel method based on the fuzzy C-means clustering to calculate the maximal Lyapunov exponent from small data. Acta Phys Sin 2016;65(2):42-8 [in Chinese)].

[66] Bao HY, Yang JD, Zhao GL, Zeng W, Liu YN, Yang WJ. Condition of setting surge tanks in hydropower plants - a review. Renew Sustain Energy Rev 2018;81: 2059-70.

[67] Liu QZ, Peng SZ. Surge tank of hydropower plant. Beijing: Water Resources and Electric Power Press; 1995 [in Chinese)].

[68] Zhou JZ, Zhang YC, Zheng Y, Xu YH. Synergetic governing controller design for the hydraulic turbine governing system with complex conduit system. J Franklin Inst 2018;355:4131-46.

[69] Yu Y. Analysis of discriminant calculation results of surge tank in Chinese and American hydropower code. Theoretical Research in Urban Construction 2018; (24):199 [in Chinese)].

[70] National Energy Administration of China, Nb/T 35021 - Design code of surge chamber of hydropower stations 2014. [in Chinese)].

[71] Bao HY. Research on setting condition of surge chamber and operation control of the hydropower station. Wuhan: Wuhan University; 2010 [in Chinese)].

[72] Xiao GY. New Development of pumped storage power station technology in Japan. Adv Sci Technol Water Resour 2003;23(1):61-5 [in Chinese)].

[73] Wang ZZ, Wang JL, Zhao YL. Analysis on the necessary formula of setting up surge tank for hydropower station. Journal of Northwest A \&F Univer sity( Na t. Sci.Ed. ) 2008;36(8):218-22.

[74] France PW. Comparison between experimental and numerical investigations of the motion of the water surface in a model surge tank. Adv Water Resour 1977;1 (1):49-51.

[75] France PW. Surge tank water level variations following rapid valve opening. Adv Water Resour 1980;3(1):41-3.

[76] France PW. Mathematical models for surge analysis. Eng Anal 1984;1(2):107-9.

[77] France PW. Finite element solution for mass oscillations in a surge tank on sudden valve opening. Adv Eng Software 1996;26(3):185-7.

[78] Fang HQ, Chen L, Dlakavu N, Shen ZY. Basic modeling and simulation tool for analysis of hydraulic transients in hydroelectric power plants. IEEE Trans Energy Convers 2008;23(3):834-41.

[79] Vereide K, Svingen B, Nielsen TK, Lia L. The effect of surge tank throttling on governor stability, power control, and hydraulic transients in hydropower plants. IEEE Trans Energy Convers 2017;32(1):91-8.

[80] Du GX. A simplication and application of the analytical method of water-hammer essential equation. Journal of Beijing agricultural engineering university 1987;7 (1):55-60 [in Chinese)].

[81] Huang LB. Study on the Method for calculation and the theory of water hammer. Zhengzhou: Zhengzhou University; 2012 [in Chinese)].

[82] Men CS. Study on dynamic characteristics of regulating system based on hydroturbine compound model to combined internal model and external model. Xian: xian University of Technology; 2018 [in Chinese)].

[83] Wyllie EB, Streeter VL. Fluid transients. Auckland: Mc Graw Hill International Book Co; 1978.

[84] Ju P. Theory and method of power system modeling. $1^{\text {st }}$ Beijing: Science Press; 2010 [in Chinese)].

[85] Xu BB, Chen DY, Edoardo P, Shen HJ, Park JH. Mathematical model and parametric uncertainty analysis of a hydraulic generating system. Renew Energy 2019;136:1217-30.

[86] Shen ZY. Analysis of hydro-turbine governing system. Beijing: China Water \& Power Press; 1991 [in Chinese)].

[87] Xiao Y, Chen T, Ke HY, Wang P. Simulation of turbine governing system model for various diversion systems. Electronic Sci Tech 2019;32(3):15-20 [in Chinese)].

[88] Zhang H, Chen DY, Xu BB, Wang FF. Nonlinear modeling and dynamic analysis of hydro-turbine governing system in the process of load rejection transient. Energy Convers Manag 2015;90:128-37.

[89] Chen ZH, Yuan XH, Tian H, Ji B. Improved gravitational search algorithm for parameter identification of water turbine regulation system. Energy Convers Manag 2014;78:306-15.

[90] Zhang H. Dynamic modelling and stability analysis of a hydro-turbine governing system. Yangling: Northwest A\&F University; 2016 [in Chinese)].

[91] Li HH. Modelling and dynamic analysis of a hydraulic generation system in large fluctuation process. Yangling: Northwest A\&F University; 2018 [in Chinese)].

[92] Wang Y. The research of transient process of long tunnel pressure diversion type power station base on Matlab. Zhengzhou: North China University of Water Resources and Electric Power; 2015 [in Chinese)].

[93] Xia X, Ni W, Sang YJ. A novel analysis method for fault diagnosis of hydro-turbine governing system. P I Mech Eng O-J Ris 2017;231(2):164-71.

[94] Chang JS. Transition process of hydraulic machinery. Beijing: Machinery Industry Press; 1991 [in Chinese)].

[95] Shen ZY. Hydro-turbine governing System. $3^{\text {rd }}$ rd. Beijing: China Water \& Power Press; 2008 [in Chinese)].

[96] Li HH, Chen DY, Zhang H, Wang FF, Ba DD. Nonlinear modeling and dynamic analysis of a hydro-turbine governing system in the process of sudden load increase transient. Mech Syst Signal Process 2016;80:414-28.

[97] Zhang H, Chen DY, Guo PC, Luo XQ, George A. A novel surface-cluster approach towards transient modeling of hydro-turbine governing systems in the start-up process. Energy Convers Manag 2018;165:861-8. 
[98] IEEE Group. Hydraulic turbine and turbine control models for system dynamic studies. IEEE Trans Power Syst 1992;7(1):167-79.

[99] Men CS, Nan HP. Improvement of Francis turbine internal characteristic model and its expanding application on outer characteristic. Trans Chin Soc Agric Eng 2017;33(7):58-66 [in Chinese)].

[100] Wang XF, Fang WL, Du ZC. Modern power system analysis. Science Press; 2003 [in Chinese)].

[101] Xu BB, Wang FF, Chen DY, Zhang H. Hamiltonian modeling of multi-hydroturbine governing systems with sharing common penstock and dynamic analyses under shock load. Energy Convers Manag 2016;108:478-87.

[102] Zhou HW, Yu JJ. The defect treatment of the tracking function of the microcomputer governor of the hydropower station. Small hydro power 2016;(6): 59-60 [in Chinese)].

[103] Wu QQ, Zhang LK, Ma ZY. A model establishment and numerical simulation of dynamic coupled hydraulic-mechanical-electric-structural system for hydropower station. Nonlinear Dynam 2017;87:459-74.

[104] Fang H, Chen L, Shen Z. Application of an improved PSO algorithm to optimal tuning of PID gains for water turbine governor. Energy Convers Manag 2011;52 (4):1763-70.

[105] Jiang C, Ma Y, Wang C. PID controller parameters optimization of hydro-turbine governing systems using deterministic-chaotic-mutation evolutionary programming (DCMEP). Energy Convers Manag 2006;47(9-10):1222-30.

[106] Cheng YC, Ye LQ, Chuang F, Cai WY. Anthropormorphic intelligent PID control and its application in the hydro turbine governor. In: 1st international conference on machine learning and cybernetics. vol. 1; 2002. p. 391-5.

[107] Li ZH, Ye LQ, Wei SP, Malik OP, Hope GS, Hancock GC. Fault tolerance aspects of a highly reliable microprocessor-based water turbine governor. IEEE Trans Energy Convers 1992;7(1):1-7.

[108] Li CS, Zhou JZ, Xiao J, Xiao H. Hydraulic turbine governing system identification using T-S fuzzy model optimized by chaotic gravitational search algorithm. Eng Appl Artif Intell 2013;26:2073-82.

[109] Yu XD, Zhang J, Fan CY, Chen S. Stability analysis of governor-turbine-hydraulic system by state space method and graph theory. Energy 2016;114:613-22.

[110] Liu XL, Liu C. Eigenanalysis of oscillatory instability of a hydropower plant including water conduit dynamics. IEEE Trans Power Syst 2007;22:675-7.

[111] Yang WJ, Norrlund P, Chung CY, Yang JD, Lundin U. Eigen-analysis of hydraulicmechanical-electrical coupling mechanism for small signal stability of hydropower plant. Renew Energy 2018;115:1014-25.

[112] Mercier T, Hardy C, Van Tichelen P, Olivier M, De Jaeger E. Control of variablespeed pumps used as turbines for flexible grid-connected power generation. Elec Power Syst Res 2019;176(1):105962.

[113] Li DH, Tang BQ, Chen YP, Deng CH. Online quasi real -time stability control system of power system and its application. Elec Power Sci Eng 2003;1:18-22 [in Chinese)].

[114] Tan Y. Development of Neutron station device module of regional stability control system based on online quasi real time strategy. Changsha: Hunan University; 2003 [in Chinese)].

[115] Wand Y. Research on dynamic parameter identification and transient stability constrained emergency control. Hangzhou: Zhejiang University; 2014 [in Chinese)].

[116] Li CS, Zhang N, Lai XJ, Zhou JZ, Xu YH. Design of a fractional-order PID controller for a pumped storage unit using a gravitational search algorithm based on the Cauchy and Gaussian mutation. Inf Sci 2017;396:162-81.

[117] Chen ZH, Yuan XH, Ji B, Wang PT, Tian H. Design of a fractional order PID controller for hydraulic turbine regulating system using chaotic non-dominated sorting genetic algorithm II. Energy Convers Manag 2014;84:390-404.

[118] Yuan XH, Chen ZH, Yuan YB, Huang YH, Li XS, Li WW. Sliding mode controller of hydraulic generator regulating system based on the input/output feedback linearization method. Math Comput Simulat 2016;119:18-34.
[119] Ma CY, Liu CZ, Zhang XZ, Sun YZ, Wu WB, Jin X. Fixed-time feedback control of the hydraulic turbine governing system. Complexity 2018:8767158.

[120] Mahmoud M, Dutton K, Denman M. Design and simulation of a nonlinear fuzzy controller for a hydropower plant. Elec Power Syst Res 2005;73:87-99.

[121] Zhang YM, Jiang J. Bibliographical review on reconfigurable fault-tolerant control systems. Annu Rev Contr 2008;32:229-52.

[122] Yu X, Fu Y, Li P, Zhang YM. Fault-tolerant aircraft control based on selfconstructing fuzzy neural networks and multivariable SMC under actuator faults. IEEE Trans Fuzzy Syst 2018;26:2324-35.

[123] Kalmari J, Backman J, Visala A. Nonlinear model predictive control of hydraulic forestry crane with automatic sway damping. Comput Electron Agric 2014;109: $36-45$.

[124] Feng C, Chang L, Li CS, Ding T, Mai ZJ. Controller optimization approach using LSTM-based identification model for pumped-storage units. IEEE Access 2019;7: 32714-27.

[125] Zhou JZ, Zhang N, Li CS, Zhang YC, Lai XJ. An adaptive Takagi-Sugeno fuzzy model-based generalized predictive controller for pumped-storage unit. IEEE Access 2019;7:103538-55.

[126] Shah P, Agashe S. Review of fractional PID controller. Mechatronics 2016;38: $29-41$.

[127] Xu YH, Zhou JZ, Xue XM, Fu WL, Zhu WL, Li CS. An adaptively fast fuzzy fractional order PID control for pumped storage hydro unit using improved gravitational search algorithm. Energy Convers Manag 2016;111:67-78.

[128] Simani S, Alvisi S, Venturini M. Data-driven design of a fault tolerant fuzzy controller for a simulated hydroelectric system. IFAC-PapersOnLine 2015;48-21: $1090-5$.

[129] Lee EB, Markus L. Foundations of optimal control theory. New York: Wiley; 1967.

[130] Chen CC, Shaw L. On receding horizon feedback control. Automatica 1982;18: 349-52.

[131] Xiao ZH, Meng SL, Lu N, Malik OP. One-step-ahead predictive control for hydroturbine governor. Math Probl Eng 2015:382954.

[132] Wang W, Xu J, Zhao X. Analysis on peak load regulation status for coal-fired power plants in China. South Energ Constr 2017;4(1):18-24 [in Chinese)].

[133] Xu BB, Chen DY, Behrens P, Ye W, Guo PC, Luo XQ. Modeling oscillation modal interaction in a hydroelectric generating system. Energy Convers Manag 2018; 174:208-17.

[134] Trivedi C, Gandhi B, Michel JC. Effect of transients on Francis turbine runner life: a review. J Hydraul Res 2013;2:121-32.

[135] Rezghi A, Riasi A, Tazraei P. Multi-objective optimization of hydraulic transient condition in a pump-turbine hydropower considering the wicket-gates closing law and the surge tank position. Renew Energy 2020;148:478-91.

[136] Nicolet C. Hydroacoustic modelling and numerical simulation of unsteady operation of hydroelectric systems. PhD thesis. École Polytechnique Fédérale de Lausanne; 2007.

[137] Zhang CH, You JF, Tai R, Wang X, Liu Y, Cheng YG. CFD simulations of pumpedtrip runaway process pressure pulsation of a model pump-turbine. J Hydroelectr Eng 2020;39(4):62-72 [in Chinese)].

[138] Li ZJ. Research on the unsteady flow characteristics and cavitation influence in the transient process of the pump-turbine. Beijing: Tsinghua University; 2017 [in Chinese)].

[139] Perez-Diaz JI, Chazarra M, Garcia-Gonzalez J, Cavazzini G, Stoppato A. Trend and challenges in the operation of pumped-storage hydropower plants. Renew Sustain Energy Rev 2015;44:767-84.

[140] Sarasua JI, Perez-Diaz JI, Wilhelmi JR, Sanchez-Fernandez JA. Dynamic response and governor tuning of a long penstock pumped-storage hydropower plant equipped with a pump-turbine and a doubly fed induction generator. Energy Convers Manag 2015;106:151-64.

[141] Shi Q. Research on the key technology of hydraulic stability of the hydro-turbine for the reconstruction of Fengman power plant. Harbin: Harbin Institute of Technology; 2017 [in Chinese)]. 